San Jose State University

SJSU ScholarWorks

\title{
A Communication Intervention in a City Government Organization Using the Appreciative Inquiry Theory Focusing on Communication, Teamwork, and Leadership to Improve Work Group Performance
}

Mary T. Figone

San Jose State University

Follow this and additional works at: https://scholarworks.sjsu.edu/etd_projects

Part of the Public Administration Commons

\section{Recommended Citation}

Figone, Mary T., "A Communication Intervention in a City Government Organization Using the Appreciative Inquiry Theory Focusing on Communication, Teamwork, and Leadership to Improve Work Group Performance" (2010). Master's Projects. 217. DOI: https://doi.org/10.31979/etd.emr9-fp6e https://scholarworks.sjsu.edu/etd_projects/217

This Master's Project is brought to you for free and open access by the Master's Theses and Graduate Research at SJSU ScholarWorks. It has been accepted for inclusion in Master's Projects by an authorized administrator of SJSU ScholarWorks. For more information, please contact scholarworks@sjsu.edu. 


\title{
A Communication Intervention in a City Government Organization Using the Appreciative Inquiry Theory Focusing on Communication, Teamwork, and Leadership to Improve Work Group Performance
}

\section{Research Paper}

A Thesis Quality Research Project Submitted in Partial Fulfillment of the Requirements for the Master of Public Administration

\author{
Mary T. Figone
}

$07 / 16 / 10$

Advisor: Dr. Frances Edwards, Political Science Department

Reader: Dr. Federico Varona, Communication Studies Department 


\section{Table of Contents}

Introduction....................................................................

Methodology.............................................................

Literature Review......................................................... 10

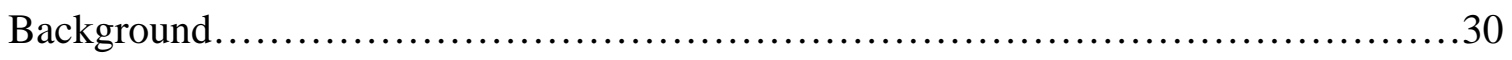

Findings: Case Data.......................................................33

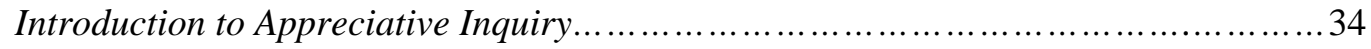

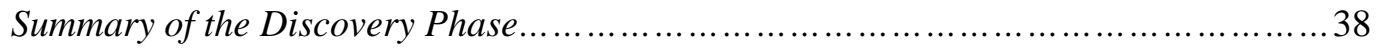

Summary of the Dream Phase............................................................. 71

Summary of the Design Phase ...........................................................74

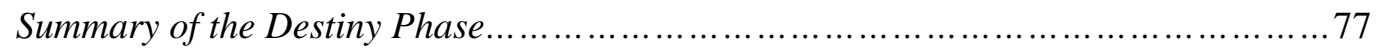

Summary Findings........................................................ 82

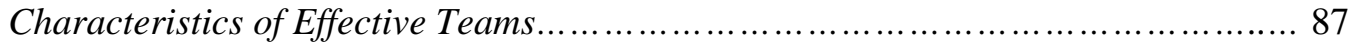

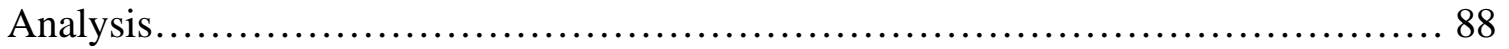

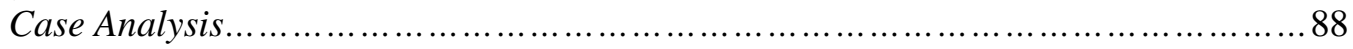

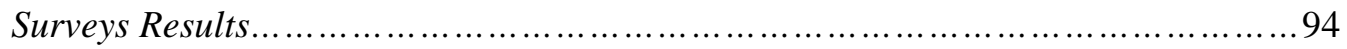

Lessons Learned......................................................... 99

Conclusion............................................................ 102

References.............................................................. 105

Appendices................................................................ 108

Appendix A - Agreement to Participate in Research....................................108

Appendix B - ECS Staff Survey...................................................... 110

Appendix C - ECS Staff Pre-Intervention Survey and Results..........................111

Appendix D - ECS Staff Post-Intervention Survey and Results..........................114

Appendix E -- Other Key Staff Survey................................................118

Appendix F - Other Key Staff Pre-Intervention Survey and Results.....................119 
Appendix G - Other Key Staff Post-Intervention Survey and Results....................125

Appendix H - Introduction to AI (Power Point)...........................................131

Appendix I-Discovery Phase: AI Themes Summary Chart.............................132

Appendix J - Personal Discovery (Power Point).........................................133

Appendix K-ECS Staff Procedures.................................................... 136

Appendix L - ECS Team Contract............................................. 138

Appendix M - The New Workplace: Where Are We Going? Checklist..................... 139 


\section{Introduction}

Public agencies struggle with a variety of barriers to success and

efficiency. Two of them are employee attitude and performance. Progressive

discipline has traditionally been the method for trying to change employee

behavior.

The progressive discipline model was developed in the 1930s in response to the National Labor Relations Act (NLRA) of 1935. The NLRA required that discipline and discharge be based on "just cause." This model follows four progressive steps to address identical offenses committed by an employee. First, an oral warning is issued as an informal reprimand. This is to fulfill correctivetraining purposes. Recommendations are that managers keep notes of what transpired during this initial meeting. The second step, a written warning is more serious and official. It summarizes the previous oral attempts. The written feedback is discussed with the employee and then placed in the employee's personnel binder (Holley \& Jennings, pp. 308-309).

The third step is suspension. The purpose of this layoff without pay is to impress on the employee the seriousness of the offense and the necessity of change. The final step is termination. Unlike the previous steps, termination is not a corrective measure. Dismissal is used only when the previous three steps have failed to help the employee change or the offense is of a highly serious nature (Pulich, p. 3).

Progressive discipline has often led to grievances and hostility in the work

place. In the 1980’s, David Cooperrider evaluated the problem of improving working conditions through a more positive approach and created Appreciative Inquiry (AI), a technique designed to demonstrate that workers are valued while at the same time working toward improvements in efficiency and interpersonal relations. 
The purpose of this paper is to present the AI concepts as they apply to public administration, and to offer a case study of its application in a Bay Area city. This research paper is divided into 10 sections as follows: 1.) Methodology, 2.) Literature Review, 3.) Background, 4.) Case Data, 5.) Findings, 6.) Analysis, 7.) Lessons Learned, 8.) Conclusion, 9.) References, and 10.) Appendices.

According to Cooperrider, et al. (2008) in Appreciative Inquiry Handbook - For Leaders of Change, in its most practical construction,
AI is a form of organizational study that selectively seeks to locate, highlight, and illuminate what are referred to as the life-giving forces of the organization's existence, its positive core. AI seeks out the exceptional best of "what is"(Discovery) to help ignite the collective imagination of "what might be" (Dream). The aim is to generate new knowledge of a collectively desired future. It carries forth the vision in ways that successfully translate images into possibilities, intentions into reality, and beliefs into practice (pp. 4-5).

Simply stated, the AI theory focuses on looking at the strengths of individuals, teams, the organization, and building on those strengths, as opposed to looking at weaknesses and trying to "fix" the perceived weaknesses. It is an organizational development change tool that uses positive questions to bring out the best in a person, in work groups, and organizations. The inquiry requires formulating positive questions and including the work group in helping to shape its positive future. Goals for an AI application include aligning the strengths of the team members; building camaraderie and trust; establishing team norms; celebrating team successes; clarifying both internal and external customer requirements; aligning the strengths in the face of cultural differences; 
creating the overall team vision and goals; creating a team identity and enhancing pride; and energizing team meetings.

AI is working as a parallel theoretical paradigm to the positive psychology movement and it is also an international movement. The University of Pennsylvania Positive Psychology Center web site defines the movement this way:

Positive Psychology is the scientific study of the strengths and virtues that enable individuals and communities to thrive. This field is founded on the belief that people want to lead meaningful and fulfilling lives, to cultivate what is best within them, and to enhance their experiences of love, work, and play.

It is gaining the support of both funding sources and educational institutions.

Why has this occurred? In Whitney \& Trosten-Bloom (2002), The Power of Appreciative Inquiry: A Practical Guide to Positive Change, they said that:

It seems that psychologists, like organizational development consultants, have recognized that human systems move into the direction of what they study. In order to contribute constructively to human and societal well-being, we need to develop a vocabulary of joy, hope, and health. The not-so-subtle shift toward positive psychology, along with Appreciative Inquiry, may well revolutionize the way that we live, work, and organize our families, communities, and businesses (p. 85).

Cooperrider, et al. (2008) in Appreciative Inquiry Handbook - For Leaders of Change discusses the four parts to this model: "Discovery, Dream, Design, and Destiny. They are known as the AI '4-D' Cycle” (p. 5).

Figure 1: The Affirmative Topic Choice Diagram on the next page graphically depicts the AI phases. 


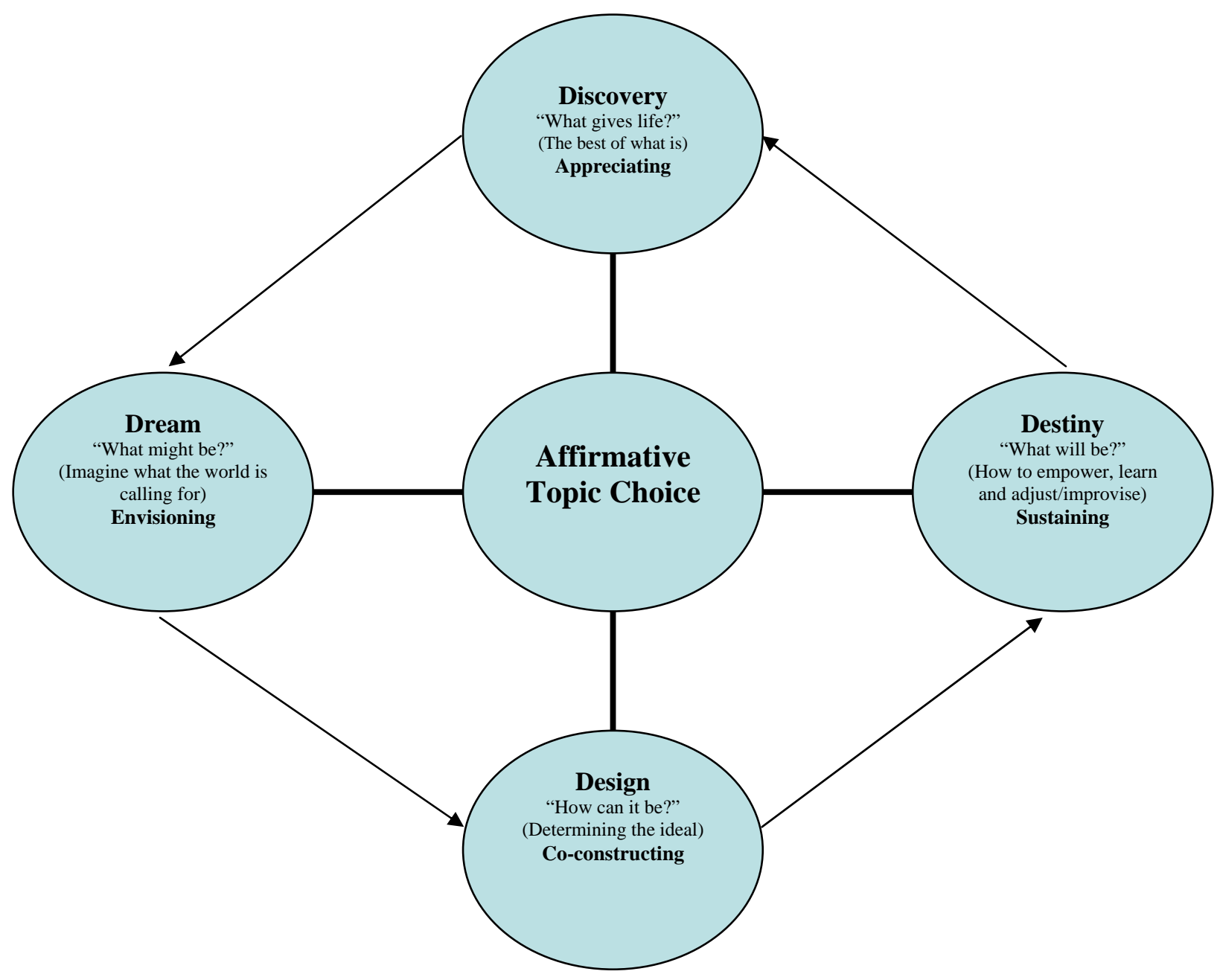

Figure 1: Source: Cooperrider \& Whitney, Appreciative Inquiry Handbook - For Leaders of Change, p. 5.

This AI positive model has worked well in organizations like GTE

Telecommunications, Avon Mexico, City of Longmont, Colorado, DTE Energy Services,

Fairmont Minerals, Hunter Douglas Window Fashions Division, Imagine Chicago,

Jefferson Wells, John Deere Harvester, Lancaster County, Pennsylvania Historical

Society, Lawrence Technological University, McDonald’s, Milton Hershey School,

NASA, Newark Beth Israel Medical Center, North American Steel, Inc., Nutrimental, 
Save the Children, United Nations, United Religious Initiative, United States Agency for International Development (USAID), United States Navy, Utah Education System, and World Vision Relief and Development (Cooperrider, Whitney, \& Stavros, pp. XXIIXXVII). The aforementioned organizations are just a small subset of the Appreciative Inquiries Initiative list.

One local Bay Area city was experiencing challenges in one of its principal departments with employee attitude, efficiency, and inter-relationships. The lack of communication, teamwork, and individual leadership demonstrated by the support staff group was adversely impacting the core services of the department. This environment offered an opportunity for the conduct of an application of AI techniques, and a chance to evaluate changes that came about as a result of this application. This experience using AI techniques and instruments is documented in this case study.

This research project, which culminated in a case study, enabled the researcher/manager of the group to apply theories and techniques from the MPA program, as well as information from the graduate-level Organizational Communication seminar.

It is important to note that when the researcher started to supervise these five employees she chose the name for the group as "Excellent Customer Service” (ECS) Staff as opposed to Support Staff. This was done intentionally because the researcher knew that these five workers could provide excellent customer service. They all had good customer service skills, which some of them had chosen not to use in a long time. 


\section{Methodology}

The methodology for this research project is a case study of the application of AI theory, and an analysis of whether it was effective in that specific case in altering employee behavior. The AI theory has four elements, which are: Discovery, Dream, Design, and Destiny. The first step in the case study was to develop the supporting documents, including an AI interview guide to use for the one-on-one appreciative interviews with the five support staff members, to be referred to as employees $1,2,3,4$, and 5, focusing on the areas of communication, teamwork, and leadership. These appreciative interviews were conducted to discover the strengths of the team. The next phases - Dream, Design, and Destiny involved helping the group to positively envision and shape where this team's future lies.

Pre- and post-AI intervention surveys were administered to both the support staff (ECS) team members and some key departmental members to use as a gauge of improvement over a five month period. The qualitative findings from these surveys are in Appendices B-G. The results are also analyzed in the Findings section under Surveys Results. 


\section{Literature Review}

The premise of this case study was to apply AI theory in order to improve a City Government Organization work group performance focusing on creating an effective team. The review of the literature included AI theory along with information on effective teams, communication, leadership, the cognitive aspects of anger and mood, understanding cultural diversity, public administrators and qualitative research, public service motivation, and dealing with difficult people. All of these topics were relevant to this case study and assisted the researcher in understanding the theory that she was putting into practice and opened her mind to other available resources and new possibilities in these areas.

\section{Appreciative Inquiry Theory}

The AI experience opened the door to the following six freedoms which the participants could take with them if they were open minded and so desired. According to Whitney \& Trosten-Bloom (2002) in The Power of Appreciative Inquiry: A Practical Guide to Positive Change, through the liberation of power, "AI creates a selfperpetuating momentum for positive change — a positive revolution.” The AI Freedoms are: 1.) Freedom to Be Known in Relationship; 2.) Freedom to Be Heard; 3.) Freedom to Dream in Community; 4.) Freedom to Choose to Contribute; 5.) Freedom to Act with Support; and 6.) Freedom to Be Positive. AI works because it unleashes all of the six freedoms over the course of just one complete 4-D Cycle” (p. 60).

In Appreciative Organization by Anderson, et al. (2008) when valuing is dominant the following are the six results that normally occur: “1.) We recognize that we are valued by others; 2.) We communicate openly and enthusiastically; 3.) We go "the 
extra mile;” 4.) We are willingly accountable with others; 5.) We become more trusting and valuing of others; and 6.) We are more willing to take risks” (p. 61).

In Reed (2007), Appreciative Inquiry: Research for Change she stated:

“Appreciative Inquiry focuses on supporting people getting together to tell stories of positive development in their work that they can build on” (p. 42). Once the data was collected from the four phases of the AI process it was time for the researcher to make sense of the data.

Jan Reed explains further:

The purpose of making sense of information in AI is to organize it in ways that will help researchers understand what people feel they have achieved and how this might be helped to happen again. This means that when researchers explore and synthesize the information collected through AI, they are looking for ideas, expressed or evident, that will help address these issues. As part of this process, we might also look at factors that people have identified as being unhelpful or examples that they have offered of things not going well, but this would be in the interest of adding depth and detail to appreciation, rather than being a starting point for analysis (p. 139).

When analyzing the data Jan Reed (2007) stated:

This involves looking within and across settings to identify learning that is specific to each setting and learning that summarizes dynamics across environments. To think this through, it is useful to look at some of the debates in case study methodology, in which similar questions arise (p. 148).

In Appreciative Inquiry: A Positive Approach to Building Cooperative Capacity,

Barrett \& Fry (2005) discussed:

What we have learned over the past two decades, after hundreds of experiments, is that AI is a powerful, strengthbased, and collaborative approach to facilitating organizational change and growth that is rapid, sustainable, and transformative. AI ignites this positive change because all humans do possess a "rich reservoir" of cooperative potential, waiting to be unleashed. The essence of building 
cooperative capacity in human systems is to put the spotlight and questions on the good work, best outcomes, and the most attractive aspects in that system. People engaged in this inquiry will naturally and quickly connect with their most positive beliefs about human groups and their potential to work, grow, dream, and celebrate together. They will naturally seek ways to move in directions that allow for more and more of that potential to be realized. The system's capacity to cooperate around multiple initiatives will expand (p. 101).

In Appreciative Inquiry: Change at the Speed of Imagination by Watkins \& Mohr (2001), they discussed the five generic processes for AI as follows: "The other half of the DNA of AI is the five generic processes for applying it as a framework for organization change. We use the term "generic processes" as a way of drawing attention to the essence of what AI is about while emphasizing the flexibility of these processes. The five generic processes are:

1. Choose the positive as the focus of inquiry;

2. Inquire into stories of life-giving forces;

3. Locate themes that appear in the stories and select topics for further inquiry;

4. Create shared images for a preferred future; and

5. Find innovative ways to create that future” (p.39).

Watkins \& Mohr in Appreciative Inquiry: Change at the Speed of Imagination

(2001) also talked about the Destiny Phase of the AI process as:

THE WORK OF THIS FOURTH CORE PROCESS of AI is to engage as many organization members as possible in co-creating a shared image or vision of a preferred future. The creation of this future image comes directly from the stories or special moments and the resultant themes or life-giving forces identified in the third core process [Design Phase]. The invitation is to imagine an organization in which those special moments of exceptional vitality found in the stories become the norm rather than the exception.

The creation of the shared image of the preferred future often progresses through two stages: (1) articulation of the dream for the organization by 
creating a visual image and a written image of the most desired future for the organization as a whole and (2) generation and description of an organization structure (social architecture) that helps make the desired future a reality (pp. 133-134).

Whitney \& Trosten-Bloom (2002) in The Power of Appreciative Inquiry: A

Practical Guide to Positive Change, discussed the eight principles of Appreciative

Inquiry as:

When it comes to Appreciative Inquiry, principles and practice go hand in hand. The practice of Appreciative Inquiry is informed by a series of eight principles - essential beliefs and values about human organizing and change. These principles, in turn, evolve as successful practice reveals new and different understandings of how positive change works.

The eight principles of Appreciative Inquiry are as unique and distinctive as the practices to which they have given birth. Derived from three generalized streams of thought-social constructionism, image theory, and grounded research - they suggest that human organizing and change is a positive, socially interactive process of discovering and crafting life-affirming, guiding images of the future (p. 51).

Figure 2: Summary of the Eight Principles of Appreciative Inquiry Table is on the next page. 
Figure 2: Summary of the Eight Principles of Appreciative Inquiry Table

\begin{tabular}{|c|c|}
\hline Principle & Definition \\
\hline $\begin{array}{l}\text { 1. The } \\
\text { Constructionist } \\
\text { Principle }\end{array}$ & $\begin{array}{l}\text { Words Create Worlds } \\
\text { - Reality, as we know it, is a subjective vs. objective state. } \\
\text { - It is socially created, through language and conversations. }\end{array}$ \\
\hline $\begin{array}{l}\text { 2. The Simultaneity } \\
\text { Principle }\end{array}$ & $\begin{array}{l}\text { Inquiry Creates Change } \\
\text { - Inquiry is intervention. } \\
\text { - The moment we ask a question, we begin to create a change. }\end{array}$ \\
\hline $\begin{array}{l}\text { 3. The Poetic } \\
\text { Principle }\end{array}$ & $\begin{array}{l}\text { We Can Choose What We Study } \\
\text { - Organizations, like open books, are endless sources of study } \\
\text { and learning. } \\
\text { - What we choose to study makes a difference. It describes- } \\
\text { even creates - the world as we know it. }\end{array}$ \\
\hline $\begin{array}{l}\text { 4. The Anticipatory } \\
\text { Principle }\end{array}$ & $\begin{array}{l}\text { Image Inspires Action } \\
\text { - Human systems move in the direction of their images of the } \\
\text { future. } \\
\text { - The more positive and hopeful the image of the future, the } \\
\text { more positive the present-day action. }\end{array}$ \\
\hline $\begin{array}{l}\text { 5. The Positive } \\
\text { Principle }\end{array}$ & $\begin{array}{l}\text { Positive Questions Lead to Positive Change } \\
\text { - Momentum for large-scale change requires large amounts of } \\
\text { positive affect and social bonding. } \\
\text { - This momentum is best generated through positive questions } \\
\text { that amplify the positive core. }\end{array}$ \\
\hline $\begin{array}{l}\text { 6. The Wholeness } \\
\text { Principle }\end{array}$ & \begin{tabular}{|l} 
Wholeness Brings Out the Best \\
- Wholeness brings out the best in people and organizations. \\
- Bringing all stakeholders together in large group forums \\
stimulates creativity and builds collective capacity.
\end{tabular} \\
\hline $\begin{array}{l}\text { 7. The Enactment } \\
\text { Principle }\end{array}$ & $\begin{array}{l}\text { Act "As If” Is Self-Fulfilling } \\
\text { - } \quad \text { To really make a change, we must "be the change we want } \\
\text { to see." } \\
\text { - } \begin{array}{l}\text { Positive change occurs when the process used to create the } \\
\text { change is a living model of the ideal future. }\end{array} \\
\end{array}$ \\
\hline $\begin{array}{l}\text { 8. The Free Choice } \\
\text { Principle }\end{array}$ & 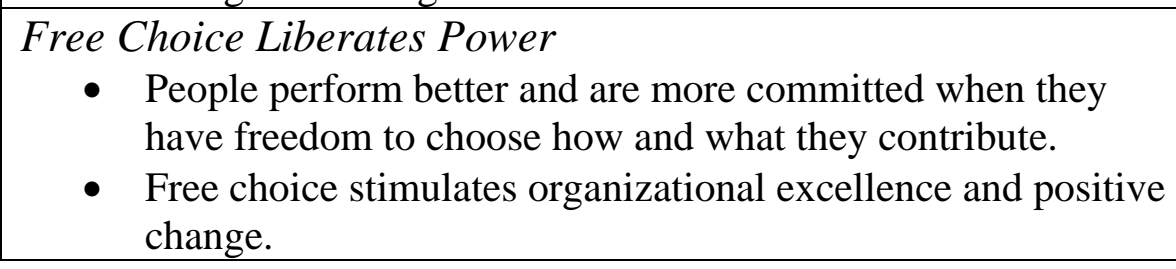 \\
\hline
\end{tabular}

Figure 2: Source: Whitney \& Trosten-Bloom (2002), The Power of Appreciative Inquiry: A Practical Guide to Positive Change, pp. 54-55. 
In Preskill \& Catsambas (2006), Reframing Evaluation Through Appreciative Inquiry they reviewed how AI evaluation had changed individuals in organizations. "The very act of participating in an appreciatively oriented evaluation increases organization members' understanding of evaluation, and hopefully the value they place on evaluative inquiry. As organization members participate in this AI process, they begin to see how their stories and experiences relate to developing the program's logic model and the evaluation's design. They also see that the evaluation's purpose and key questions are not just haphazardly determined; rather they are developed from what is learned from their stories” (p. 138).

The AI coaching process used the AI principles as well. In Appreciative Coaching: A Positive Process for Change, Binkert \& Clancy (2007), there was a quote by Helen Keller (1880-1968) American blind and deaf educator as follows: “No pessimist ever discovered the secret of the stars, or sailed an uncharted land, or opened a new doorway for the human spirit” (p. 107). In the mentoring program, created in the Design Phase, the coaches will be using appreciative coaching for the five member support team. "Language matters, especially in coaching. It is the primary tool of our profession and a powerful construct with which to work. As a method grounded in social constructionism — the notion that people create their relationships and their world through language and action-Appreciative Coaching makes extensive use of significantly positive language to generate positive feelings, actions and outcomes” (p. 192).

Cooperrider \& Whitney (1999) in Appreciative Inquiry: Collaborating for Change stated the following:

Human Change Integrity also contributes to AI's success. This is the capacity for system members to be, in Gandhi's words, "the change they want to see.” AI impacts personal, relational, and organizational 
performance profoundly and simultaneously. As individuals are interviewed they experience unfamiliar validation and support. At the relational level, the interview taps a human longing to experience and recognize meaningful connections. Once discovered, the stories, the shared experience, and the connections become part of the individuals' and the organization's identities. With AI, the organization, its members, and stakeholders transform simultaneously in relation to one another (p. 24).

AI is an alternative organizational development intervention tool. In the Appreciative Inquiry Handbook - For Leaders of Change $/ 2^{\text {nd }}$ Edition (2008), Cooperrider, Whitney, \& Stavros defined AI as: "In its most practical construction, AI is a form of organizational study that selectively seeks to locate, highlight, and illuminate what are referred to as the life-giving forces of the organization's existence, its positive core” (p. 4).

Thatchenkery \& Chowdhry (2007) in Appreciative Inquiry and Knowledge Management discussed how certain elements of change had to be in place for groups and organizations. "Change agents must learn the art of creating enough energy and desire for change and grounding the desired new behaviors, practices, or structures into something specific, measurable, and concrete. Above all, they need to think in the long term that is, how long can these changes be sustained? Is there enough commitment on the part of the stakeholders to go through with the change process?” (p. 67).

In Appreciative Inquiry - A Positive Revolution in Change by Cooperrider \& Whitney (2005), the role of the participants was stated as follows:

The primary role of participants in an AI process is to be students of organizational life. AI engages all levels of an organization and its stakeholders in a cooperative learning and co creation process. To be a student of organizational life emphasizes curiosity and learning in the most pragmatic sense. AI is the study of the best of what has been and what can be. In the process, best practices inspire action toward dreams for a collective future that are grounded in reality and hence believable and feasible. 
AI is an invitation to a positive revolution, to meeting others who might otherwise be considered "them," and to learn and co create a world that works for all. AI participants are often surprised by how much they learn about themselves as well as others in the process. Openness to learning is often an exciting and life-giving outcome of AI (p. 48).

There were four questions from Orem, et al. (2007) in Appreciative Coaching: A Positive Process for Change that would be asked during the initial session as follows: “1.) What gives life to you now?; 2.) Describe a high point or peak experience in your life or work up to now.; 3.) What do you most value about yourself, your relationships, and the nature of your work?; and 4.) What one or two things do you want more of in your life?” (p. 97).

In Cooperrider \& Whitney (1999), Appreciative Inquiry: Collaborating for Change, "Our hypothesis is that when AI is conducted as a whole systems approach moving through the 4-D Cycle, the positive core becomes the explicit and common property of all” (p. 23). The chart below in Figure 3 compares the “normal” problem solving phases versus the Appreciative Inquiry cycle.

Figure 3: Problem Solving and Appreciative Inquiry

\begin{tabular}{|c|c|}
\hline Problem Solving & Appreciative Inquiry \\
\hline $\begin{array}{c}\text { "Felt Need" Identification } \\
\text { of Problem }\end{array}$ & $\begin{array}{c}\text { Appreciating and Valuing } \\
\text { the Best of "What Is" }\end{array}$ \\
\hline Analysis of Causes & Envisioning "What Might Be" \\
\hline Action Planning (Treatment) & Dialoguing "What Should Be" \\
\hline Basic Assumption: & Basic Assumption: \\
An Organization Is a Problem to Be & An Organization Is a Mystery to be \\
Solved & Embraced \\
\hline
\end{tabular}

Figure 3: Source: Cooperrider \& Whitney (1999), Appreciative Inquiry: Collaborating For Change, p. 23. 


\section{$\underline{\text { Effective Teams }}$}

There have been many studies identifying the characteristics of effective teams.

One of these studies that was done by Larson \& LaFasto was found in Organizational Communication in an Age of Globalization by Cheney, et al. (2004), which found eight characteristics of effective teams. They were as follows:

1.) A clear, elevating goal: a clear sense of purpose, mission, or vision that members find inspiring and challenging;

2.) Unified commitment (to group and purpose): a sense of dedication to the team's goal and commitment to the team and its members;

3.) Results-driven structure: the organization, or structure, of the team is aligned with its purpose and the nature of its task; 4.) Collaborative climate: members have a sense of working together and a commitment to supporting each other; the focus is on achieving the team's goals, not just one's own assigned tasks; 5.) Competent team members: in total, the team members with the technical skills and interpersonal skills to achieve its goals; 6.) Standards of excellence: members expect outstanding levels of performance from the team and from themselves individually; 7.) External support and recognition: the team receives support from the larger organization by getting the resources needed to perform and by being recognized for its achievements; and 8.) Principled leadership: team leaders are respected for having a strong sense of principles or ethics (p. 227).

This was an area that was found to be extremely important in another study that

focused on top management teams in Europe and the United Kingdom looking at how teams can be more effective. In Organizational Communication in an Age of

Globalization by Cheney, et al. (2004), the outcomes of this study were as follows:

1.) Interpersonal relationships among members must be good, with members understanding and respecting one another's styles and values; 2.) The team must have the capacity and willingness to engage in open discussion of important and potentially contentious issues; 3 .) The team must be approachable and open to feedback and criticism by others external to the team; 4.) Members must have sufficient discipline and cohesion to implement and pursue decisions on which they agree; and 5.) Members must have the capacity to discuss and understand both long- and short-term issues of concern to the organization (p. 227). 
Busche (1998) in his article: Appreciative Inquiry with Teams in the

Organizational Development Journal reported:

A simple process based on the principles of AI that I've referred to as the "best team" inquiry has been experimentally shown to affect groups positively. I tried to show how it helps members of new teams establish personal identity and differentiate themselves. Ongoing teams can benefit from a "best team" inquiry in several ways. It can help to create a safe gateway into difficult issues for a group. When lack of appreciation is the issue, it can create so much tension in members that they deal up their resentments and expectations. It can aid the development of shared mental maps of group success. It can help create affirming, generative images that allow for a different discourse, a different set of understandings and opportunities to materialize for a group. This can be therapeutic for a group stuck in a paradox. In working with teams to develop affirming, generative images, an AI into something other than teams is often appropriate and can have very positive impacts on groups and their members. As a change process AI is a powerful "pull" strategy and can sometimes transform a relationship or a group (p. 41).

In Appreciative Inquiry: Rethinking Human Organizations Toward a Positive

Theory of Change by Cooperrider, et al. (2000), there was a chapter on Appreciative Inquiry With Teams by Gervase R. Bushe, Ph.D. This chapter discussed the "Best Team” approach as well as how to do an inquiry for a group who has certain issues. There was a section on "Paradoxical intervention into groups stuck in undisclosed resentment.” When there is a paradoxical intervention the outcome does not look at new shared focuses. "Rather it creates a cathartic release by forcing people into a paradoxical tension. By focusing on what they are not feeling (appreciation for each other) the issues that are causing the discordant feelings cannot be contained. This is a powerful intervention and not for the timid. But then so is stepping into the middle of a hostile, frustrated team” (pp. 189-190). 
Whitney, et al. (2004) in Appreciative Team Building: Positive Questions to Bring

out the Best of Your Team discussed the dimensions that influence team effectiveness as

follows:

So transforming the day-to-day interactions in teams to be more positive than negative is a means to achieving a productive balance between the team's focus on itself and its environment, between seeking understanding and asserting authentic beliefs and opinions. This shift in the pattern of discourse, in turn, lends to measurable success and value added for the organization.

The dimensions that influence team effectiveness are: 1.) clear and shared goals or purpose; 2.) clear and shared roles/responsibilities; 3.) supportive and empowering relationships; 4.) clear and shared procedures; 5.) nurturing and challenging leadership; 6.) evolving energy and spirit; 7.) productivity and performance; and 8.) complete, purposeful and uplifting communication (pp. 5-6).

Whitney, et al. also talked about eleven ways to use positive questions. "Your day as a manager is full of opportunities. Whether you manage people or projects, the work you do gets done through communication, through the interactions and conversations you have with people. The following eleven ways to use positive questions come from the experience of managers in organizations around the world.

1.) Get Staff Meetings Off to a Good Start; 2.) Coach for High Performance; 3.) Transform "Problem Talk" to "Possibility Talk;"

4.) Create Dialogue to Foster Shared Meaning; 5.) Demonstrate Positive Intent and Trust with Customers; 6.) Create a Learning Organization; 7.) Build High Performance Teams; 8.) Conduct Project Reviews that Make a Difference; 9.) Build Self-Esteem; 10.) Plan a Course of Action for the Future; and 11.) Create Your Own Interview Guide (pp. 1-5).

In Covey’s (1989) The Seven Habits of Highly Effective People, he introduced the seven habits as: 1.) Be proactive; 2.) Begin with the end in mind; 3.) Put first things first; 4.) Think win/win; 5.) Seek first to understand, then to be understood;

6.) Synergize; and 7.) Sharpen the saw. These seven habits form a foundation of change. They can be used in one's personal and/or work life. 
The paradigm of interdependence is also discussed in this book. Covey explained interdependence as: "effective interdependence can only be built on a foundation of true independence. Private Victory precedes Public Victory. Algebra comes before calculus.”

Covey had a theory that we each had an emotional bank account. "An emotional bank account is a metaphor that describes the amount of trust that's been built up in a relationship. It's the feeling of safeness you have with another human being” (p. 185). There are six major deposits that can go into the "emotional bank account” they are: 1.) Understanding the individual (This is one of the most important deposits.); 2.) Attending to the little things (Respecting others and doing small acts of kindness.);

3.) Keeping commitments (A major deposit is keeping promises and commitments. Conversely, not keeping one of them is a major withdrawal.); 4.) Clarifying expectations (How can you do a great job if you do not know what the expectations are or they do not make sense?); 5.) Showing personal integrity (This generates trust and can bring many other types of deposits.); and 6.) Apologizing sincerely when you make a withdrawal (The key word is being sincere and doing the apology right away.)

These were all important theories and the researcher did her best to apply them on a daily basis to increase the emotional bank accounts of the ECS team members.

\section{$\underline{\text { Communication }}$}

Hammond \& Mayfield (2004), in The Thin Book of Naming Elephants noted regarding communication:

“A constructive dialogue would create an open and respectful forum for discussing different views, realities and formerly taboo subjects. It is the place people learn to agree to disagree without shutting down future conversations. Dialogue is a form 
of inquiry that assumes people see the world differently. In a dialogue frame, each

person assumes he or she can learn something new from others and become better informed as a result” (p. 39).

Scott \& Jaffe (1995) in Managing Change At Work, provided many examples of how to face changes head on and how to communicate changes to the staff. One of the key elements for change management was to gain control. Communication was important to this process:

You can't move through change and keep previous levels of tight control over your people. You can gain control over change by giving it up. In effective organizations, people share basic goals and communicate clearly, directly and regularly about what they are doing. Each person goes about his or her work with greater flexibility than is common in less effective organizations. If you manage an effective organization during change, you will benefit by exercising a new type of leadership-less as a controller and more as a coordinator, focuser and facilitator. Only you and the group together can make things happen. This takes place when you learn how to intelligently delegate some of your control to the team (p. 17).

\section{$\underline{\text { Leadership }}$}

In the Encyclopedia of Positive Questions, Volume 1: Using Appreciative Inquiry to Bring Out the Best in Your Organization (2001), by Whitney, et al. discussed using their book's questions and seeing the best in others as follows:

This practical handbook has forty questions that can transform your approach to leadership and organizational development. Not one of the questions has the word "problem" in it. Indeed, the only thing the questions are meant to do is help people discover strengths, assets, and best practices. And this is deliberate. Put simply, the message of this resource is this: positive results will suddenly appear for you virtually everywhere the more you are able to see the best in others (your children, colleagues, partners, competitors), see the best in yourself, and then ask questions that bring out and amplify the best in your organization (p. xi). 
In Scott \& Jaffe’s (1995), Managing Change at Work there was also The New

Workplace: Where Are We Going? Checklist (Appendix M) which included some of the elements that can be expected to be seen in most organizations in the year 2000 and beyond. The researcher noted with the number one those elements that this team thought it still needed to have more of in order to have a good workplace. Also, the researcher/supervisor noted with the number two those elements the researcher thought still needed to occur in the organization.

In PUBLIC ADMINISTRATION: Understanding Management, Politics, and Law in the Public Sector by Rosenbloom \& Kravchuk (2005), there was discussion about leadership and what was the best style to use as follows:

Tannenbaum and Schmidt reasoned that the most suitable leadership styles in any given context would depend on the managers, the subordinates, or nonmanagers, and the organizational structure.

An important conclusion is that the leadership style should be determined by the congruence of forces in the manager and those in the subordinates.

The NPM takes yet another view. It opposes hierarchy and puts considerable emphasis on teams. Teams are formal work groups that may be composed of employees at all levels - managerial, supervisory, and rank and file. If the use of teams becomes characteristic of public administration in the future, they should offer fertile ground for gaining a much better understanding of leadership (p. 159).

\section{Cognitive Aspect of Anger/Mood Issues}

The following Figure 4 shows the five aspects of life experiences that effect team behavior. The cognitive aspects of anger issues are explained in Mind Over Mood Change How You Feel by Changing the Way You Think by Greenberger \& Padesky (1995): “Anger is linked to a perception of damage or hurt and to a belief that important 
rules have been violated. We become angry if we think we have been treated unfairly, hurt unnecessarily, or prevented from obtaining something we expected to achieve. Notice the emphasis on fairness, reasonableness, and expectation. It is not simply the hurt or damage that causes anger, but the violation of rules and expectations” (p. 193).

Figure 4: Five Aspects of Your Life Experiences

\section{ENVIRONMENT}

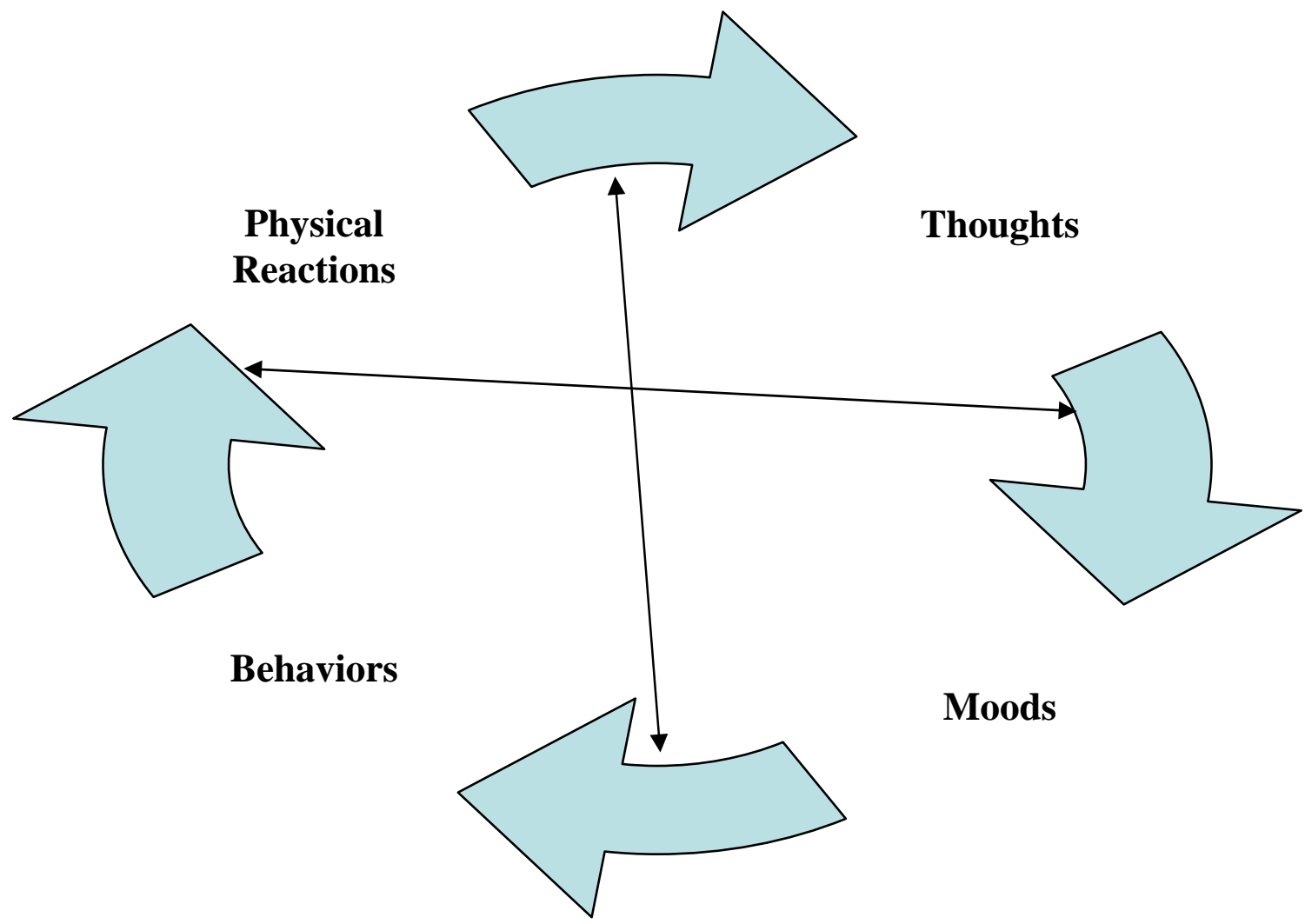

Figure 4: Source: Greenberger \& Padesky (1995), Mind Over Mood - Change How You Feel by Changing the Way You Think, p. 4.

Every individual experiences some of the five aspects of life on a daily basis.

Greenberger \& Padesky (1995) explained this phenomenon in Mind Over Mood Change How You Feel by Changing the Way You Think as: 
Thoughts are beliefs, images, and memories, moods, behaviors, physical reactions, and environment (past and present). Notice that the five areas are interconnected. The connecting lines show that each different aspect of a person's life influences all others. For example, changes in our behavior influence how we think and also how we feel (both physically and emotionally). Behavior changes can also change our environment. Understanding how these five parts of our lives interact can help us understand our problems (p. 4).

The anger profile below in Figure 5 provides some insight into what people are thinking about when they are having these four reactions.

\section{Figure 5. Anger Profile}

\section{Thoughts}

Others are threatening or hurtful

Rules have been violated

Others are treating me unfairly

\section{Behaviors}

Defend/Resist

Attack/Argue

Withdraw (to punish or protect)

\section{Physical Reactions}

Tight muscles

Increased blood pressure

Increased heart rate

\section{Moods}

Irritable

Angry

Enraged

Figure 5: Source: Greenberger \& Padesky, (1995), Mind Over Mood - Change How You Feel by Changing the Way You Think, p. 192.

\section{$\underline{\text { Cultural Differences }}$}

In Law’s book (1993), The Wolf Shall Dwell with the Lamb he discussed understanding cultural differences in the perception of power.

"There is a clear perception of personal power among the different cultures. The perception of personal power is our own understanding of our ability to change our environment. In terms of interpersonal relationships, the perception of power is our 
sense of authority and ability to influence and control others. More often than not, this

perception of power is unconscious” (p. 14).

\section{$\underline{\text { Public Administrators and Research }}$}

The results of this case study were qualitative in nature. Larry Luton (2005) in a case study presented to ASPA also identified ten (overlapping, but noteworthy) reasons that public administrators do qualitative research. They are:

1.) We seek both positivist and constructivist knowledge; 2.) We seek knowledge that is not limited to what science can tell us; 3.) We seek knowledge that is pragmatic; 4.) We seek knowledge that is action-oriented; 5.) We recognize the importance of context; 6.) We seek to understand causation; 7.) We have a desire for success in both our academic and our practitioner career; 8.) We want to be engaged with our subject matter (e.g., ASPA); 9.) We want our research to be relevant to practitioners; and 10.) We want to engage practitioners.

Commitment was an element needed by the ECS Team members to have a healthy team. In Appreciative Inquiry and Knowledge Management by Thatchenkery \& Chowdhry (2007) it was found that: “Commitment, inspiration, and groundedness are thus elements that must be present in a healthy future-present scenario (Thatchenkery, 2005). Without commitment, the new possibility will not materialize” (p. 67).

\section{$\underline{\text { Public Service Motivation }}$}

In the Public Policy and Administration journal there was an article by Horton \& Hondeghem (2006), on Public Service Motivation and Commitment. In public service, motivation as a universal concept was discussed as:

Today, public services no longer appear secure as government policies of privatization, downsizing and outsourcing have introduced great uncertainty into them. At one time, public services were attractive as employers of choice as they offered secure employment, good pay and terms and conditions and opportunity to serve the community. Career progression has also been weakened by the increase in lateral recruitment and the emphasis on appointment on merit rather than seniority. The roles 
of civil servants and other public officials are also changing and they are now often required to manage in increasingly competitive market conditions with a focus on customer service. Finally, the skills and competencies required of new 'public managers' are very different from those expected of classic administrators and public servants (pp. 1-2).

Brewer, et al. (2000) also contributed to the theory by identifying four different types of public service motivation. Samaritans are highly motivated to help those in need of aid and in particular the underprivileged within society. Communitarians are motivated by a sense of civic responsibility and public service. Patriots are inspired to act in the name of a greater good such as the public or national interest. Finally, humanitarians are motivated by a desire for social justice. It is clear from these definitions that there are some core values, which are identified with public service motivation. These are public service, social and civic responsibility, public and national interest and self-sacrifice (pp. 34).

\section{Dealing with Difficult People}

In Applied H.R.M. (Human Resources Management) Research by Raynes (2001),

Predicting Difficult Employees: The Relationship between Vocational Interests, Selfesteem, and Problem Communication Styles, there are suggestions on how to deal with difficult people, e.g., Jerks, as follows:

According to Meier (1993), other employees should work on their responses to difficult people and question why they allow difficult people to make them feel intimidated, angry, or hurt. He believes there are steps that others can take that will protect them from Jerks. These steps include not letting comments, opinions, or behaviors of Second Degree Jerks affect their self-concept. He suggests that people who learn to think positively about their own strengths will be less affected by the behavior of Jerks. Meier appears to be recommending that the best way to handle difficult employees is to improve one's own self-esteem (p. 46).

In LaFevor's dissertation (1999), discipline was identified as a process:

Disciplinary practices are necessary to enhance organizational citizenship behavior and secure and sustain compliance to organizational policies and rules (Niehoff \& Moorman, 1993). 
Specifically, Kravit (1986) has outlined the essential goals of a disciplinary system. These include:

1. to maintain standards of performance and conduct in accordance with reasonable rules and expectations;

2. to improve conduct or performance that falls below acceptable levels in order to maintain efficiency and protect the employee's good standing;

3. to avoid discharge with the consequent waste of the employer's investment in the employee and the almost inevitable harm to the employee's reputation and economic interests; and

4. to meld individuals into effective work groups.

Therefore, through the appropriate administration of a disciplinary system, undesirable employment consequences such as high turnover, loss of morale, lowered job performance and employee loss of respect for management can be averted (Traverneir \& Kleiner, 1988). Despite potential risks in the absence of formal disciplinary policies, approximately $10 \%$ of all companies have no procedures for employee discipline and dismissals (Upton, 1987). Beary (1985) has noted the first primary step towards an effective disciplinary program is the institution of a clear and concise policy on discipline.

The topics covered in this literature review were on AI theory, along with information on effective teams, communication, leadership, the cognitive aspects of anger and mood, understanding cultural diversity, public administrators and qualitative research, public service motivation, and dealing with difficult people.

AI could work extremely well with a mature group of individuals who did not have significant personal and behavioral issues. In this case, the AI process was able to pacify these individuals because they enjoyed feeling that they were driving each phase of the AI process.

In contrast, this group experienced a five year undocumented case study of progressive discipline from 2003 to 2008 that was consistently applied to them. This did 
nothing more than motivate the group members to file grievances against their supervisor. They acted out and were consciously fighting the system.

The reality is that a combination of AI and progressive discipline were needed for this group. They did not want to conform into a functioning team because they felt they would lose their individualism in the process and they were being "forced" into being something they did not want to be.

Appreciative Inquiry allowed these case study participants the opportunities to feel the six AI Freedoms and for these struggling employees it gave them some positive hope. The literature review provided the researcher with more diverse tools to use that she tried sometimes successfully and other times not as successfully in parallel with the AI, but the whole process enlightened her on methods to use to work with this "complicated" and oftentimes, "challenging” group. 


\section{Background}

In a principal department of a Bay Area city, there was a five member support staff. These individuals were supposed to work together as a team to provide support to the various sections within the department.

The demographics of this rich culturally diverse group were as follows: the members, all female, ranged in age from 39 to 53 years old. There were two individuals born in other countries, one in Malaysia and the other in Tonga, who migrated to the United States with their families. There was a person of African-American heritage and two others who were of European-American descent. This cultural diversity had been a challenge in the past, but it was turned into an opportunity to draw the strengths out of this rich cultural diversity of individuals to strengthen this work group.

Approximately ten years ago, this support staff worked together as a team, exhibited individual leadership qualities, and used effective communication. Over the years with changes in personnel, this team has devolved into a disparate group of individuals who were strong in certain ways, yet they exhibited a lack of trust towards each other. They also lacked consistency in following the city’s personnel procedures, including following basic protocol on arriving to work on time, taking inappropriate extended breaks, failing to notify others when leaving the work area, and exhibiting various other deficiencies.

Some of the members of this team believed that they were indispensable; meaning that if something happened to them that the city would not be able to function without their unique contributions. There were three subsets which made up this group. There were two pairs of support staff who were very good friends and only wanted that person to back them up if they were out of the office. The newest member of this support group 
had been in the group for approximately six years and has always been alienated by them. In fact, when she first started both groups combined forces and were verbally attacking her.

The challenges with the support staff have created difficulties over the past nine years, including causing a rapid rotation of managers. The longest supervisor they had most recently was for five years. This was a brand new Administrative Assistant with little supervisory experience who was thrust into being their manager. They did not like her management style and immediately ganged up and verbally attacked her. She also had Union grievances filed against her. For example, one of the five member support group even filed a grievance against the supervisor for the performance review given by her. The manager did her best to try and bring this group together. She brought a consultant in to work on gauging their personalities and work styles, and the consultant did provide feedback on areas to improve the overall team effectiveness of the group. Unfortunately, these areas were never followed up on. The consultant's efforts were unsuccessful mainly because the work group members had decided amongst themselves that they would make the effort fail. Finally, the manager became "burned out" and the support staff was split up back to their original section managers. The section managers were very involved with the technical aspects of their roles so they did not have time to micromanage their support staff members and also be involved in working out the minor details with the other managers. This arrangement was ineffective.

In March 2009, a new manager was assigned to supervise the two support staff members (employees 2 and 3) that were considered to be the "best" of the group. This researcher/manager did not have any long-term supervisory experience. These two employees had not been hostile to her since she did not micromanage their activities. She 
had witnessed them both coming into the office late. When she gave them their performance reviews she also collected information from the managers who they reported to for most of the year. Since they both perceived themselves as being "perfect" they did not want any "blemishes" on their reviews. One of them convinced the new supervisor to wordsmith an area that had been noted for her improvement. The new supervisor had to spend extra time with the other person to ensure that she clearly heard and felt comfortable with the areas noted for her improvement.

This group has brought challenges to their managers in the past. The goal of the AI communication intervention was to build a stronger work team of more responsible and productive employees. The definition of team in the American Heritage College Dictionary is “a group organized to work together” (2002, p.1414). The case study will reveal whether AI has succeeded in creating a team out of the disparate individuals assigned to this manager. 


\section{Findings: Case Data}

The AI process officially began on 10/20/09 with an Introduction to AI kick-off meeting for the four group members present. The pre-surveys were distributed in hard copy to the ECS staff and to the Other Key staff using SurveyMonkey on 09/15/09. (Surveys were routinely done to gauge the support staff's performance.) The most recent pre-intervention surveys were issued on 09/15/09 and completed on 09/29/10, and were used as a benchmark for this case study. The first three AI phases - Discovery, Dream, and Design - were completed by 01/05/10. There is an Appreciative Inquiry timeline table in this section on page 37 which provides the significant dates, participants, and milestones in the AI process.

The Destiny Phase is an ongoing one. In this phase, the programs created by the ECS team in the Design Phase were implemented, with the understanding that this phase will continue on as long as the team members are actively participating to keep the programs going. The post-intervention surveys were distributed by email with a link to SurveyMonkey on 02/16/10 with the surveys completed by 02/28/10.

The post-intervention survey results were analyzed in early March 2010. The survey results were summarized and shared with the support team, so they could hear what they were perceived to be doing well and areas that they could change to make their internal customers more satisfied. The AI phase results were presented by each participant. The numbers 1 through 5 were assigned to the participants and were consistently used throughout this case, so that both confidentiality and clarity were maintained in the analysis. This case analysis has provided the individual and group highlights from the AI process and the researcher's observations and conclusions on the effectiveness of the AI application both individually and collectively on this work group. 


\section{Introduction to Appreciative Inquiry}

On 10/20/09, the AI process was presented to four of the five support staff members. (One support staff member employee 5 was ill so the presentation was given to her on 11/03/09 separately, prior to her beginning her AI Discovery interview.) A Power Point presentation (Appendix H) which was an Introduction to AI was shown, and the Agreement to Participate in Research (Appendix A) was read to the group by the researcher. Once this was completed, the researcher asked the group if they had any questions.

Three of the four members (employees 2, 3, and 4) present for the Introduction to AI, started to complain very loudly that they did not like the way the researcher presented the subject to them; how they were always the "guinea pigs;" and each of them took turns yelling at the researcher regarding their displeasure about having to participate in the AI process. This extremely negative experience lasted for approximately 25 minutes until they each reluctantly agreed to participate in the AI to help the researcher in her "school work." When it was time for the meeting to end, one of the dissatisfied group members, employee 2, said, "It was great to be behind closed doors so we could really tell you (the researcher) how we feel!"

Later that same day, two of the ECS group members came into the researcher's

office (employees 3 and 4). One of them, employee 4, said, "She wanted the researcher to help her move up in the organization.” Another of them, employee 3, popped her head into the researcher's office and exclaimed, "That was the best meeting I have ever been in!” and she also let the researcher know how wonderful she felt about yelling at her with the rest of her group. There was one silent group member, employee 1, at the meeting table who came by the researcher's office a few days later. Employee 1 said that the 
Appreciative Inquiry process sounded like a really good one and she was excited about participating in it! She hoped that it would have a positive effect on her work group. She also thought all of the negative comments were very inappropriate from the other members of the group toward the researcher in the AI introductory meeting.

The researcher was both shocked and disheartened about most of the group’s initial response to the AI theory. The consensus from employees 2, 3, and 4 of the group was that the researcher should have just told them it was a "school homework assignment” and they would have agreed to do it with no problem. The reality was that it was a research project in partial fulfillment of the researcher’s Master of Public Administration Degree (MPA) requirements, which is much more important than a homework assignment. In retrospect, due to the lack of professionalism in the group, the researcher would not have down played this fact and simply stated what it was and not had a Power Point presentation, just an introduction and a question and answer session.

The researcher was feeling a little nervous prior to the introductory AI meeting. This was because she was not sure what emotions would erupt in this meeting from the participants. The researcher also underwent outpatient surgery and treatment within an hour after this extremely negative meeting. If the researcher had shown any emotion, especially anger, while the group was verbally abusing her at this meeting, then the group would have felt that they had "beat" her and would not have agreed to participate in the appreciative inquiry process. Right or wrong, the researcher earned those employees' respect. The fact that the researcher stood her ground and allowed employees 2, 3, and 4 to vent opened up a communication channel that would have taken years to develop. These employees- rightfully or not- felt that they had no voice. The AI process showed them that they did and it could be a positive voice. 
The main point of contention was found in the Agreement to Participate in Research (Appendix A) where it stated, "While you are expected to participate in AI as part of your job, you are not required to participate in the research that I will do to evaluate AI's application.” These 13 bolded words were interpreted by them to mean that they had did not have a say about whether they did the AI or not, and they wanted to have a voice about participating. This was a common theme that the researcher found throughout the AI process - these employees wanted the ability to be heard and be part of the decision making process. Yet they did not want to conform to any "rules," and they felt they were entitled to everything. They also want to be treated as individuals and not thought of as a "team," even though their work necessitated them to function as a unit. The next page has the Appreciative Inquiry timeline table. 


\section{Appreciative Inquiry Timeline Table}

\begin{tabular}{|c|c|c|}
\hline Date(s) & Activity & Participant(s)/Comments \\
\hline $09 / 30-10 / 15 / 09$ & $\begin{array}{l}\text { Pre-intervention copies distributed to } \\
\text { Other Key Staff. SurveyMonkey used for } \\
\text { ECS Team }\end{array}$ & $\begin{array}{l}\text { Researcher, ECS Team, and } \\
\text { Other Key Staff }\end{array}$ \\
\hline $10 / 01 / 09$ & $\begin{array}{l}\text { Did fun team-building activity at a local } \\
\text { restaurant }\end{array}$ & Researcher and ECS Team \\
\hline $10 / 20 / 09$ & $\begin{array}{l}\text { AI Introduction Kick-off Meeting to ECS } \\
\text { Team }\end{array}$ & Researcher and ECS Team \\
\hline $10 / 21-11 / 03 / 09$ & $\begin{array}{l}\text { Appreciative Inquiry Interview Discovery } \\
\text { Phase Sessions }\end{array}$ & Researcher and ECS Team \\
\hline 11/02-11/04/09 & $\begin{array}{l}\text { Discovery Phase Data Analysis to } \\
\text { identify common themes }\end{array}$ & Researcher \\
\hline $11 / 10-11 / 24 / 09$ & $\begin{array}{l}\text { Group Theme Analysis - AI Dream } \\
\text { Phase }\end{array}$ & Researcher and ECS Team \\
\hline $11 / 10 / 09$ & Personal Discovery (Appendix J) & $\begin{array}{l}\text { Researcher and ECS Team- } \\
\text { employees } 1,2,4 \text {, and } 5 \\
\text { participated and enjoyed }\end{array}$ \\
\hline 11/17-11/19/09 & AI Discovery Phase Analysis & $\begin{array}{l}\text { As a group they looked at the } \\
\text { positive core and the themes } \\
\text { from the AI interviews }\end{array}$ \\
\hline $11 / 19 / 09$ & AI Discovery Phase Results & Researcher and ECS Team \\
\hline $11 / 24 / 09$ & AI Dream Phase Analysis & Researcher and ECS Team \\
\hline $11 / 30-12 / 22 / 09$ & $\begin{array}{l}\text { Focused on team-building using } \\
\text { appreciative discoveries }\end{array}$ & Researcher and ECS Team \\
\hline $12 / 09 / 09$ & Project Tour & $\begin{array}{l}\text { The group enjoyed seeing the } \\
\text { results of their labor }\end{array}$ \\
\hline $12 / 15 / 09$ & $\begin{array}{l}\text { AI Discovery Phase results review and } \\
\text { Dream Phase theme analysis }\end{array}$ & $\begin{array}{l}\text { Researcher and ECS Team- } \\
\text { moved into AI Design Phase. }\end{array}$ \\
\hline 01/05/10 \& 01/12/10 & $\begin{array}{l}\text { AI Design Phase - Brainstorming and } \\
\text { creating programs sessions for the future } \\
\text { growth of the team }\end{array}$ & Researcher and ECS Team \\
\hline $02 / 11-02 / 12 / 10$ & $\begin{array}{l}\text { AI Destiny Phase - project } \\
\text { implementation updates }\end{array}$ & Researcher and ECS Team \\
\hline 02/12/10-Ongoing & AI Destiny Phase updates & $\begin{array}{l}\text { One-on-one meetings to obtain } \\
\text { status updates on the Design } \\
\text { programs }\end{array}$ \\
\hline $02 / 16-02 / 28 / 10$ & $\begin{array}{l}\text { Post-intervention surveys emailed using } \\
\text { SurveyMonkey link }\end{array}$ & $\begin{array}{l}\text { Researcher, ECS Team, and } \\
\text { Other Key Staff }\end{array}$ \\
\hline $03 / 05 / 10$ & $\begin{array}{l}\text { Post-intervention surveys results } \\
\text { analyzed }\end{array}$ & Researcher \\
\hline $03 / 10 / 10$ & $\begin{array}{l}\text { Reviewed results of post-intervention } \\
\text { surveys }\end{array}$ & Researcher and ECS Team \\
\hline
\end{tabular}




\section{Summary of the Discovery Phase}

Overall, the AI interviews were positive. The researcher noted that when the group members were separated they were much calmer and less aggressive. They tended to get a "gang mentality" trying to out do each other when in a group. They also showed less professionalism and respect to the researcher and even to other employees when they were all together in a group.

The five AI interviews averaged approximately 1 hour in length. During the interviews, most of the participants really opened up and at times appeared almost glowing as they shared their positive stories. Employee 5 was more reticent as she struggled to find stories that she thought were relevant to the questions. The opening question was, "What are the core factors that give life to this organization?” This question brought extra emotion from some of them due to the fact that this organization was going through Union contract negotiations and all of the five subjects were Union members. Some of them talked about a time when they felt the organization really cared about the employees and there were moments of negativity, but this shifted when they moved into the focal areas. A Summary of the Discovery Phase themes is on pages 6769, and a Discovery Phase: AI Themes Summary Chart of individual responses is in Appendix I.

The appreciative interview guide questions and individual responses follow for employees 1-5. They also contain the employee number and interview meeting date(s). The Dream, Design, and Destiny observations will follow all of the five employee interview guides. The collective observations of the researcher for the whole group during the Dream, Design, and Destiny Phases will follow these individual case observations. 
Appreciative Inquiry Interview 1: Employee 1

The first AI Discovery session was on 10/21/09 with employee \#1. This employee was the most positive about the AI process. She was relaxed and appeared confident as she answered the AI questions. This employee is the most mature member of the group. She did not have the gang mentality; in fact, she distanced herself from the other group members. She was also the newest member of the group and had worked at this organization for over five years. Her strengths were her individuality, her ability to know what right and wrong was, and her loyalty to her employer. She came in to work on the Union’s “Volunteer Day” which was a pre-strike action, even though all of the other group members were out of the office. When the group was working on the AI Dream and Design Phases this employee actively participated and she took a leadership role in the Design Phase.

Following is the Appreciative Interview Guide for employee 1 with the questions and her responses during the interview. 


\section{Appreciative Inquiry Interview Guide}

\section{Interviewee Number: 1}

Interview Date: 10/21/09

\section{Introduction}

Today we will be participating in an Appreciative Inquiry interview that will focus on your individual strengths, the strengths of your work group, and the organizational strengths. The questions will look at how things were at their best and through your stories it will help to build a brighter future for you and your work group. The topics are on: Effective/Compelling Communication; Creating and Sustaining Positive Energy; Respect for People; and Winning Teamwork. It is important to note that two instrumental components of becoming an excellent leader are being able to find and use your positive energy and both giving and receiving respect from other people.

If you do not understand a question that I ask, please ask me for clarification.

So the best thing you can do for me in this conversation is to think about, remember, and tell me details about the things you have seen, heard of, or imagined - either here or in other organizations - that really work. At the end of this interview I will provide you with my handwritten notes so that you can verify if I have captured the essence of your answers. The answers to the Appreciative Inquiry interview will be kept confidential.

Do you have any questions? No.

Thank you for participating in this appreciative interview that is focused on positive change!

\section{Opening}

1.) Please tell me about your initial attraction to this organization. What inspired you to join?

The job security and the benefit package inspired me to join this organization. She had also heard positive things from her relatives that had worked here. She grew up and lived in this city and it provided her with lots of good memories. She cared about this city and this made the difference for her. 
2.) What is the core factor that gives life to this organization - without it the organization would not be the same?

The past strengths of this organization was that it cared about the employees; it valued me; it was nice how the executive people acknowledged me as an individual; and they knew me by name. This made me feel like I was part of a family.

\section{Topics}

\section{1.) Effective/Compelling Communication}

We communicate on a daily basis both verbally and nonverbally. Effective communication is critical to getting the job done and for the health of the organization. Compelling communication occurs when information is shared in ways to improve or strengthen relationships among people, and increase their ability to do a good job. It also helps to strengthen relationships that can build bridges, it focuses on the work to be done, and it conveys a sense of caring and commitment.

Compelling communication goes both ways and it is the ultimate backbone of organizational success.

a.) Please tell me about a time when compelling communication allowed you and another person to really connect and to work together exceptionally well. What were the key factors that contributed to the success of this beautiful experience?

She worked for a start-up company where there was a small core group. It started with four employees. It was a lot of experience for her at a young age. Her manager trusted her, there were positive feelings, enthusiasm, and trust in her abilities. There was constant communication and no apprehension about communicating amongst them. There was a lot of trust.

b.) What are the key components of effective communication?

The key components of effective communication are:

1.) Tactfulness - commend first, then give constructive criticism so communication is balanced. (Using the sandwich effect.)

2.) Sincerity - When you commend someone making sure you are doing it sincerely. 
3.) Listening more than telling. (80/20 rule of being a good listener.)

4.) Being honest.

\section{2.) Creating and Sustaining Positive Energy}

This organization like others is much healthier and alive when there is positive, fun energy flowing through it. When this happens the positive energy is contagious amongst the employees and the organization has a vibrant spirit.

a.) Please tell me about a time when you experienced positive energy that was infectious.

When she worked at a software company it was a team environment where they answered 800 customer service calls a day. She felt that her group was always willing to help and answer questions. Each person felt comfortable with each other. There were no grudges. Everyone was friendly and happy to be with each other. There were eight people in this work group. There was also diversity in the group men and women.

b.) What were the key factors that contributed to this energetic experience?

The key factors that contributed to this energetic experience were the open and positive attitudes, and they worked hard and played hard e.g., golf/lunch - they played games and had other team activities that everyone enjoyed.

\section{3.) Respect for People}

A common theme for organizations that are recognized as great places to work is the amount of deep respect shared by the people both internally and externally to the organization. Respect is found in interpersonal relationships within departments, interdepartmentally, and across positions. There is a strong respect that is shared in the organization.

People feel respected when they are involved in conversations and decision-making, when they are listened to, when they are valued for their opinions and ideas, and when they are given the opportunity to fully participate in achieving the organization's goals. Giving and receiving respect is contagious and does not need to follow any hierarchal structure. People who feel respected in turn respect others including colleagues and 
customers. Some of the other by-products from respecting others are: self-confidence, enhancing teamwork, and facilitating organizational success.

a.) Please tell me about a time when you experienced a strong sense of respect from another person.

It was from a supervisor: she respected her opinion and asked her opinion often. She also confided in her on some personal areas.

b.) What were the key factors that contributed to this wonderful experience?

The key factors that contributed to this wonderful experience were frequent communication and taking personal time with her. She felt that her supervisor thought she saw the bigger picture so she was able to think outside of the box and be a good sounding board to bounce her ideas off of.

\section{4.) Winning Teamwork}

Teamwork is an essential ingredient for success in any organization. We are individuals, but we need to effectively and openly communicate and work together to achieve common goals. In this way the organization can thrive. Individuals can also achieve so much more by working together in harmony within their work groups, in their departments, across departments, assisting customers, and in the organization in general.

a.) Please describe a time that you had seen or been a part of a team that exemplified excellent teamwork.

See answer to 2a regarding the software company.

b.) What were the key factors that contributed to the success of this winning teamwork experience?

The key factors that contributed to the success of this winning teamwork experience were respect; open communication; having fun together; being very positive; and no backbiting.

\section{Conclusion}

a.) If you were given three wishes, what would your wishes be in order to enhance the health and vitality of your work group? 
It should be noted that this is a dysfunctional group that wants to be dysfunctional. She would like to move away from this thinking.

Three Wishes:

1.) Wished everyone respected each other. (Respect means no backbiting, everyone getting along, no gossiping, negativity or sarcasm.)

2.) Wished everyone would be included in the group. The group should be inclusive.

3.) Wished everyone would be happy in their job and show it.

b.) If your wishes were realized and things were wonderful, what would be happening in your work group today?

Our work group would be more positive. Our attitudes would be more positive. We would strive for a common goal. Customer service levels would be much higher. There would be more joy in the work place.

c.) Do you have any additional comments or questions?

See 1a's response. She is also a big proponent of working in a work group team. She has had a lot of training on working in a team related to customer service and team-building.

Please take a few minutes to read through my notes to ensure I have captured the essence of your answers. Your answers will be kept confidential.

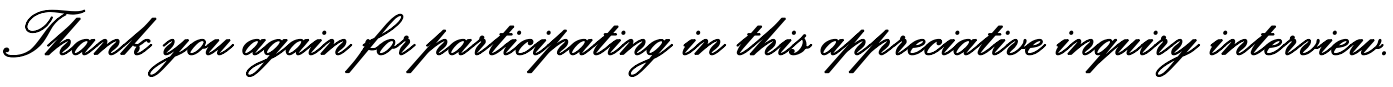




\section{Appreciative Inquiry Interview 2: Employee 2}

As soon as she sat down in the researcher's office on 10/21/09 for her AI interview employee 2 said, “Your project will fail!” The researcher did not directly comment on this remark, but instead the researcher said, "Let us give this AI interview our personal best!”

Employee 2 liked to use intimidation and manipulation. She stared down the researcher as each question was asked and when she was responding. When employee 2 was out of her element she tried to counterbalance this by making others feel threatened. The researcher just ignored this juvenile behavior and proceeded with the interview. This employee grew up in a gang neighborhood so she had the gang mentality and tried to be the ringleader with her group whenever she could. She had many (almost 10) years of experience in this department fine-tuning her intimidation and manipulation skills.

She also had some very strong skills which included her initiative to get the job done and to follow-up until the job was done. Employee 2 could have several projects going on and was able to prioritize them and get them done in a timely manner.

Sometimes she threatened and intimidated employees in other departments to get the job done. This was a problem that her supervisor was working closely with her on. When employee 2 was given an assignment she became enmeshed in it and did not want anyone else to touch the project. This was another area her supervisor worked closely on with her.

Next is the Appreciative Interview Guide for employee 2 with the questions and her responses during the interview. 


\section{Appreciative Inquiry Interview Guide}

\section{Interviewee Number: 2}

Interview Date: 10/21/09

\section{Introduction}

Today we will be participating in an Appreciative Inquiry interview that will focus on your individual strengths, the strengths of your work group, and the organizational strengths. The questions will look at how things were at their best and through your stories it will help to build a brighter future for you and your work group. The topics are on: Effective/Compelling Communication; Creating and Sustaining Positive Energy; Respect for People; and Winning Teamwork. It is important to note that two instrumental components of becoming an excellent leader are being able to find and use your positive energy and both giving and receiving respect from other people.

If you do not understand a question that I ask, please ask me for clarification.

So the best thing you can do for me in this conversation is to think about, remember, and tell me details about the things you have seen, heard of, or imagined - either here or in other organizations - that really work. At the end of this interview I will provide you with my handwritten notes so that you can verify if I have captured the essence of your answers. The answers to the Appreciative Inquiry interview will be kept confidential.

Do you have any questions? No.

Thank you for participating in this appreciative interview that is focused on positive change!

\section{Opening}

1.) Please tell me about your initial attraction to this organization. What inspired you to join?

She started as a temporary employee at an off-site city location then she was called to work temporarily in this department. Her current position opened up and then she was hired for the job.

2.) What is the core factor that gives life to this organization - without it the organization would not be the same? 
A year ago the core factor for the City was its positive core which was that it cared about its employees. They defended the employees against the community members. The City was willing to work with the employees.

\section{Topics}

\section{1.) Effective/Compelling Communication}

We communicate on a daily basis both verbally and nonverbally. Effective communication is critical to getting the job done and for the health of the organization. Compelling communication occurs when information is shared in ways to improve or strengthen relationships among people, and increase their ability to do a good job. It also helps to strengthen relationships that can build bridges, it focuses on the work to be done, and it conveys a sense of caring and commitment.

Compelling communication goes both ways and it is the ultimate backbone of organizational success.

a.) Please tell me about a time when compelling communication allowed you and another person to really connect and to work together exceptionally well. What were the key factors that contributed to the success of this beautiful experience?

There was a big success when she was part of the Zoning Ordinance Update consisting of mailing out approximately 15,000 flyers. Three other co-workers were folding and stuffing envelopes all day long. Other department staff came to help. The key factors that made this experience a success was the other department members who came to help and other staff from other departments who would help for an hour. People just started pitching in to help as soon as they were asked.

b.) What are the key components of effective communication?

The key components of effective communication are: honesty; truthfulness; anonymity; being able to listen; and conveying suggestions or advice, if warranted. 


\section{2.) Creating and Sustaining Positive Energy}

This organization like others is much healthier and alive when there is positive, fun energy flowing through it. When this happens the positive energy is contagious amongst the employees and the organization has a vibrant spirit.

a.) Please tell me about a time when you experienced positive energy that was infectious.

During the Loma Prieta earthquake, she was at work with her manager and a loan agent. When the earth began to shake her manager jumped under her desk and the loan agent was in a door jam. There was a chain reaction to their reactions.

b.) What were the key factors that contributed to this energetic experience?

The situation was not funny, but their reactions to the situation were.

\section{3.) Respect for People}

A common theme for organizations that are recognized as great places to work is the amount of deep respect shared by the people both internally and externally to the organization. Respect is found in interpersonal relationships within departments, interdepartmentally, and across positions. There is a strong respect that is shared in the organization.

People feel respected when they are involved in conversations and decision-making, when they are listened to, when they are valued for their opinions and ideas, and when they are given the opportunity to fully participate in achieving the organization's goals. Giving and receiving respect is contagious and does not need to follow any hierarchal structure. People who feel respected in turn respect others including colleagues and customers. Some of the other by-products from respecting others are: self-confidence, enhancing teamwork, and facilitating organizational success.

a.) Please tell me about a time when you experienced a strong sense of respect from another person.

She receives respect on a daily basis with thank yous both internally and externally. It helps her to get up in the morning. When a person does a job to the best of their ability and is willing to do things outside of the box, then they will get noticed and receive thank yous. Shortly after she started working at the City a customer told people to "talk with Lucy Doe because she can help you." 
b.) What were the key factors that contributed to this wonderful experience?

The key factors that contributed to this wonderful experience were that she goes above and beyond when she does her job and she receives positive feedback which are thank yous from many sources. She takes extreme pride in her work and continually strives to improve herself both professionally and personally. Finally, she always makes sure she says "please and thank you.”

\section{4.) Winning Teamwork}

Teamwork is an essential ingredient for success in any organization. We are individuals, but we need to effectively and openly communicate and work together to achieve common goals. In this way the organization can thrive. Individuals can also achieve so much more by working together in harmony within their work groups, in their departments, across departments, assisting customers, and in the organization in general.

a.) Please describe a time that you had seen or been a part of a team that exemplified excellent teamwork.

See 1a for an example, there are also many examples of mass mailings that she has participated in at this organization, and she worked at a wholesale loan company in Sacramento, CA. She managed 15 loan consultants and as a team they worked together well. She stepped in whenever it was needed. She and other team members helped.

b.) What were the key factors that contributed to the success of this winning teamwork experience?

The key factors that contributed to the success of this winning teamwork experience were the pulling together of people to work as a team; the one commonality which was getting the job done on time and correctly; there were no worries about getting the job done on time, just knowing it would get done; and having trust in co-workers that they will pull their weight. 


\section{Conclusion}

a.) If you were given three wishes, what would your wishes be in order to enhance the health and vitality of your work group?

Three Wishes:

1.) Realize that we are individuals and the jobs we are doing are different even though some are similar.

2.) Once something has been decided upon it is followed through with. Some follow through on decisions is needed.

3.) Continuity regarding the workload.

b.) If your wishes were realized and things were wonderful, what would be happening in your work group today?

1.) Everyone would be recognized for the jobs they do.

2.) Making sure that decisions get implemented.

3.) Knowing what it is that we do. We do our assigned tasks. When support staff is available then other staff can come to us for assistance.

c.) Do you have any additional comments or questions?

The support staff is not broken. We do not need a band aid. We function very well together, especially in a crisis situation.

Please take a few minutes to read through my notes to ensure I have captured the essence of your answers. Your answers will be kept confidential.






\section{Appreciative Inquiry Interview 3: Employee 3}

The next AI Discovery Phase interview was on 10/27/09 with employee 3 who had so much to share it took another session on 11/02/09 to complete her AI Discovery Phase interview. This employee was very happy and jubilant to share her answers that she gave in great detail. She appeared to enjoy reminiscing about her past jobs. She also gave supervising tips to help with this team by explaining the various personalities.

Employee 3 had worked for this organization for over 15 years. She had built up a lot of institutional knowledge in her position. She had a good attitude, but she would be actively involved in manipulating people and also in gossiping. She was a hard worker; but at times she paced herself and was observed on one occasion of putting bids on e-Bay items during her work time. She also surfed the web regularly. At times she could be very argumentative, yet she appeared knowledgeable, but often she was not correct in her assumptions. Finally, she had a know-it-all personality.

Following is the Appreciative Interview Guide for employee 3 with the questions and her responses during the interview. 


\section{Appreciative Inquiry Interview Guide}

\section{Interviewee Number: 3}

Interview Dates: 10/27/09 and 11/02/09

\section{Introduction}

Today we will be participating in an Appreciative Inquiry interview that will focus on your individual strengths, the strengths of your work group, and the organizational strengths. The questions will look at how things were at their best and through your stories it will help to build a brighter future for you and your work group. The topics are on: Effective/Compelling Communication; Creating and Sustaining Positive Energy; Respect for People; and Winning Teamwork. It is important to note that two instrumental components of becoming an excellent leader are being able to find and use your positive energy and both giving and receiving respect from other people. If you do not understand a question that I ask, please ask me for clarification.

So the best thing you can do for me in this conversation is to think about, remember, and tell me details about the things you have seen, heard of, or imagined - either here or in other organizations - that really work. At the end of this interview I will provide you with my handwritten notes so that you can verify if I have captured the essence of your answers. The answers to the Appreciative Inquiry interview will be kept confidential.

Do you have any questions? No.

Thank you for participating in this appreciative interview that is focused on positive change!

\section{Opening}

1.) Please tell me about your initial attraction to this organization. What inspired you to join?

She found a temporary position which was a front desk clerical at an off-site

community center. It was a few times a week half-time work. She liked how this

organization had the initiative to hire her even though she was not a permanent

resident.

2.) What is the core factor that gives life to this organization - without it the organization would not be the same? 
The core factors of this organization were its' diversity, the culture, the very essence of each individual employee. They make it vibrant here!

\section{Topics}

\section{1.) Effective/Compelling Communication}

We communicate on a daily basis both verbally and nonverbally. Effective communication is critical to getting the job done and for the health of the organization. Compelling communication occurs when information is shared in ways to improve or strengthen relationships among people, and increase their ability to do a good job. It also helps to strengthen relationships that can build bridges, it focuses on the work to be done, and it conveys a sense of caring and commitment.

Compelling communication goes both ways and it is the ultimate backbone of organizational success.

a.) Please tell me about a time when compelling communication allowed you and another person to really connect and to work together exceptionally well. What were the key factors that contributed to the success of this beautiful experience?

She has had many positive experiences with compelling communication. One that stands out was with a co-worker who she had been having disagreements with. They went out to lunch and talked about this and resolved their situation. She became her supervisor temporarily and offered to help her and this built another bridge. They worked and completed the project together. This gave her co-worker added feelings of accomplishment.

b.) What are the key components of effective communication?

The key components of effective communication are: listen to what people are saying to you; understand what they are trying to get at; put yourself in the other person's shoes; tell people what you are trying to say; and ask questions for additional understanding or further clarification. 


\section{2.) Creating and Sustaining Positive Energy}

This organization like others is much healthier and alive when there is positive, fun energy flowing through it. When this happens the positive energy is contagious amongst the employees and the organization has a vibrant spirit.

a.) Please tell me about a time when you experienced positive energy that was infectious.

She experienced positive energy that was infectious when she worked for another company. They had one goal and were totally focused in a positive way. It was like clock work. They enjoyed working together and framed everything in the positive. They felt like they were a family. She felt like she was always included in any event. Regardless of what position they were in the organization, they all felt proud and they celebrated their successes.

b.) What were the key factors that contributed to this energetic experience?

The factors that contributed to this energetic experience were that everybody felt they belonged, that they were important, that they were involved in everything; and they were brought together for announcements. "Knowledge is the key to success."

\section{3.) Respect for People}

A common theme for organizations that are recognized as great places to work is the amount of deep respect shared by the people both internally and externally to the organization. Respect is found in interpersonal relationships within departments, interdepartmentally, and across positions. There is a strong respect that is shared in the organization.

People feel respected when they are involved in conversations and decision-making, when they are listened to, when they are valued for their opinions and ideas, and when they are given the opportunity to fully participate in achieving the organization's goals. Giving and receiving respect is contagious and does not need to follow any hierarchal structure. People who feel respected in turn respect others including colleagues and customers. Some of the other by-products from respecting others are: self-confidence, enhancing teamwork, and facilitating organizational success.

a.) Please tell me about a time when you experienced a strong sense of respect from another person. 
She received a strong sense of respect from a friend who recommended her for a job. After that she had to build up respect for herself as a person first. She also felt that diversity training would probably be good for this organization.

b.) What were the key factors that contributed to this wonderful experience? The key factors that contributed to this wonderful experience were that the company thinking was not focused on cultural/family background, but about who you were as a person.

\section{4.) Winning Teamwork}

Teamwork is an essential ingredient for success in any organization. We are individuals, but we need to effectively and openly communicate and work together to achieve common goals. In this way the organization can thrive. Individuals can also achieve so much more by working together in harmony within their work groups, in their departments, across departments, assisting customers, and in the organization in general.

a.) Please describe a time that you had seen or been a part of a team that exemplified excellent teamwork.

There have been several situations where she was part of a team that exemplified excellent teamwork. In a private organization she had collated the maps by hand. The other departments would help during lunch and after work to hand color the 250350 maps and collate the copies that were handouts at the company meeting. This all was done on time! In the current public organization, there was a large 3,000-4,000 piece mailing for a project. It was a nice regular mailing card that had to be folded. Support staff asked for help inside and outside the department. People were willing to help. This was an example of excellent teamwork!

b.) What were the key factors that contributed to the success of this winning teamwork experience?

The key factors that contributed to the success of this winning teamwork experience were the knowledge of the project; people’s willingness to help; a common goal 
(stakeholder's involvement); availability of tools; and camaraderie regardless of the different departments.

\section{Conclusion}

a.) If you were given three wishes, what would your wishes be in order to enhance the health and vitality of your work group?

Three Wishes:

1.) More money for state of the art equipment that is readily accessible.

2.) Clear separation of work and play.

3.) One for all or none - meaning every single point of operation, process, etc. needs to apply to all.

b.) If your wishes were realized and things were wonderful, what would be happening in your work group today?

1.) Be more informed as to items that are affecting the department.

2.) Be heard in terms of suggestions recommended for streamlining efforts.

3.) Everyone protects each other up the ranks.

c.) Do you have any additional comments or questions?

We have to be consistent with everyone. We need to focus on being a green city by cutting back on copy paper usage. We need to use/upgrade our existing technology to get the word out.

Please take a few minutes to read through my notes to ensure I have captured the essence of your answers. Your answers will be kept confidential.

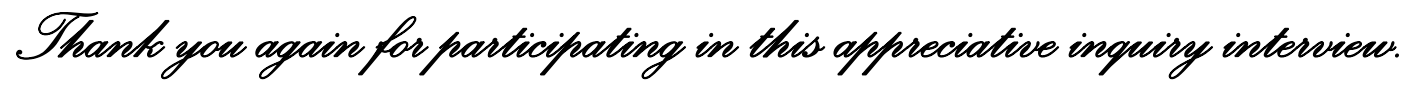




\section{Appreciative Inquiry Interview 4: Employee 4}

On the morning of 11/03/09, one of the biggest opponents to the AI process, employee 4, was interviewed as part of the Discovery Phase. She was almost angry looking and reticent about the process when it was explained to her. The researcher could feel the negativity in the room, but as the AI questions were asked she appeared to relax and towards the end of the interview she even appeared to be enjoying the interview process. Employee 4 had worked in the organization for over nine years and wanted to do her own thing at work in her own way. She lacked consistency in her work because she always wanted to fix the process, even when she did not understand the process.

Below is the Appreciative Interview Guide for employee 4 with the questions and her responses during the interview. 


\section{Appreciative Inquiry Interview Guide}

\section{Interviewee Number: 4}

Interview Date: 11/03/09

\section{Introduction}

Today we will be participating in an Appreciative Inquiry interview that will focus on your individual strengths, the strengths of your work group, and the organizational strengths. The questions will look at how things were at their best and through your stories it will help to build a brighter future for you and your work group. The topics are on: Effective/Compelling Communication; Creating and Sustaining Positive Energy; Respect for People; and Winning Teamwork. It is important to note that two instrumental components of becoming an excellent leader are being able to find and use your positive energy and both giving and receiving respect from other people.

If you do not understand a question that I ask, please ask me for clarification.

So the best thing you can do for me in this conversation is to think about, remember, and tell me details about the things you have seen, heard of, or imagined - either here or in other organizations - that really work. At the end of this interview I will provide you with my handwritten notes so that you can verify if I have captured the essence of your answers. The answers to the Appreciative Inquiry interview will be kept confidential.

Do you have any questions? No.

Thank you for participating in this appreciative interview that is focused on positive change!

\section{Opening}

1.) Please tell me about your initial attraction to this organization. What inspired you to join?

At that time, she thought city government had more structure, security, more

teamwork, and was a great place to work.

2.) What is the core factor that gives life to this organization - without it the organization would not be the same?

The people in this organization give it life, as well as the passion that people have for their work and the service to the community and residents. 


\section{Topics}

\section{1.) Effective/Compelling Communication}

We communicate on a daily basis both verbally and nonverbally. Effective communication is critical to getting the job done and for the health of the organization. Compelling communication occurs when information is shared in ways to improve or strengthen relationships among people, and increase their ability to do a good job. It also helps to strengthen relationships that can build bridges, it focuses on the work to be done, and it conveys a sense of caring and commitment.

Compelling communication goes both ways and it is the ultimate backbone of organizational success.

a.) Please tell me about a time when compelling communication allowed you and another person to really connect and to work together exceptionally well. What were the key factors that contributed to the success of this beautiful experience?

Person A was really aggressive with her communications to her. She ignored person A, then eventually went out to lunch with person A. She did not like demanding emails. Person A and she took a class together regarding email communication. There was a strong connection/bond at that initial lunch. The key factors that contributed to the success of this beautiful experience were identifying the unhelpful communication; providing examples of emails; and then the class solidified it all.

b.) What are the key components of effective communication?

The key components of effective communication are being clear and expressing yourself; having a professional approach; be open to feedback; and learning that one-sided communication does not work.

\section{2.) Creating and Sustaining Positive Energy}

This organization like others is much healthier and alive when there is positive, fun energy flowing through it. When this happens the positive energy is contagious amongst the employees and the organization has a vibrant spirit.

a.) Please tell me about a time when you experienced positive energy that was infectious. 
We used to have gatherings during lunch with outside food being brought in as well as movies. This was a place to share concerns and it was an outlet for our emotions. The support staff group enjoyed the movie together. The feelings that developed there were carried during the rest of the day. The group all looked forward to this once a month lunchtime get together. It was fun! This also improved the support staff's attitudes.

b.) What were the key factors that contributed to this energetic experience?

See answer to question 2a.

\section{3.) Respect for People}

A common theme for organizations that are recognized as great places to work is the amount of deep respect shared by the people both internally and externally to the organization. Respect is found in interpersonal relationships within departments, interdepartmentally, and across positions. There is a strong respect that is shared in the organization.

People feel respected when they are involved in conversations and decision-making, when they are listened to, when they are valued for their opinions and ideas, and when they are given the opportunity to fully participate in achieving the organization's goals. Giving and receiving respect is contagious and does not need to follow any hierarchal structure. People who feel respected in turn respect others including colleagues and customers. Some of the other by-products from respecting others are: self-confidence, enhancing teamwork, and facilitating organizational success.

a.) Please tell me about a time when you experienced a strong sense of respect from another person.

The person used to be her manager. She witnessed him being angry over avoidable or unavoidable mistakes. He had a high level of professionalism. He did not hold a grudge. He made you want to give 120 percent, so that you did not disappoint him. He was an excellent communicator.

b.) What were the key factors that contributed to this wonderful experience? See answer to question 3a. 


\section{4.) Winning Teamwork}

Teamwork is an essential ingredient for success in any organization. We are individuals, but we need to effectively and openly communicate and work together to achieve common goals. In this way the organization can thrive. Individuals can also achieve so much more by working together in harmony within their work groups, in their

departments, across departments, assisting customers, and in the organization in general.

a.) Please describe a time that you had seen or been a part of a team that exemplified excellent teamwork.

At a previous organization, they were not segregated by position titles. (It was a

24 hour operation.) If someone was sick other employees would jump in and

make sure the job was done. This worked extremely well so upper management

did not need to get involved. In the beginning, the groups were segregated, but

then all of the employees came together and bought in on the new arrangement to

all help out to get the job done. All of the employees were trustworthy so you

could trust your team members.

b.) What were the key factors that contributed to the success of this winning teamwork experience?

See answer to question 4a.

\section{Conclusion}

a.) If you were given three wishes, what would your wishes be in order to enhance the health and vitality of your work group?

Three Wishes:

1.) Wishes that her section manager (not the researcher) were more organized so that this would be a domino effect regarding time management.

2.) Wishes that there were better processes and that her work group would have more involvement in building or redoing these processes.

3.) Wishes that the morale could be lifted for the entire department e.g., better relationships with each other. Management and employees working towards a better professional relationship. 
c.) If your wishes were realized and things were wonderful, what would be happening in your work group today?

We would be functioning like a normal department. The processes we have spent so much time in changing would work.

d.) Do you have any additional comments or questions?

Every group has some level of chaos and there is hope that at the end of the chaos is a level of resolution. In this work group, the chaos leads to chaos. A strong commitment and desire to change would eradicate the chaos.

Please take a few minutes to read through my notes to ensure I have captured the essence of your answers. Your answers will be kept confidential.

Thant yper again for particifating in this affreciative inguing interview. 


\section{Appreciative Inquiry Interview 5: Employee 5}

The final AI Discovery Phase interview was in the afternoon on 11/03/09 with employee 5. This employee had a good attitude about her interview. She was relaxed and she listened intently so that she could provide her best answers. Once she answered a question, she would check with the researcher to confirm that her answer was correct. The researcher told her there were not any right or wrong answers to the questions. This employee really wanted to please the people that she supported as well as her team members. She had worked in the organization for over 15 years. In that time, she worked hard to learn new skills. She still had challenges with her spelling and grammar, but she continued to try and do her personal best at work. Her attitude after the AI process became even more positive.

Following is the Appreciative Interview Guide for employee 5 with the questions and her responses during the interview. 


\section{Appreciative Inquiry Interview Guide}

\section{Interviewee Number: 5}

Interview Date: 11/03/09

\section{Introduction}

Today we will be participating in an Appreciative Inquiry interview that will focus on your individual strengths, the strengths of your work group, and the organizational strengths. The questions will look at how things were at their best and through your stories it will help to build a brighter future for you and your work group. The topics are on: Effective/Compelling Communication; Creating and Sustaining Positive Energy; Respect for People; and Winning Teamwork. It is important to note that two instrumental components of becoming an excellent leader are being able to find and use your positive energy and both giving and receiving respect from other people.

If you do not understand a question that I ask, please ask me for clarification.

So the best thing you can do for me in this conversation is to think about, remember, and tell me details about the things you have seen, heard of, or imagined - either here or in other organizations - that really work. At the end of this interview I will provide you with my handwritten notes so that you can verify if I have captured the essence of your answers. The answers to the Appreciative Inquiry interview will be kept confidential.

Do you have any questions? No.

Thank you for participating in this appreciative interview that is focused on positive change!

\section{Opening}

1.) Please tell me about your initial attraction to this organization. What inspired you to join?

She was looking for a stable, city job. The benefits were good at that time.

2.) What is the core factor that gives life to this organization - without it the organization would not be the same?

The core factor that gives life to this organization is the staff inside the organization interacting with them and also with the public. There are positive aspects in both of them. 


\section{Topics}

\section{1.) Effective/Compelling Communication}

We communicate on a daily basis both verbally and nonverbally. Effective communication is critical to getting the job done and for the health of the organization. Compelling communication occurs when information is shared in ways to improve or strengthen relationships among people, and increase their ability to do a good job. It also helps to strengthen relationships that can build bridges, it focuses on the work to be done, and it conveys a sense of caring and commitment.

Compelling communication goes both ways and it is the ultimate backbone of organizational success.

a.) Please tell me about a time when compelling communication allowed you and another person to really connect and to work together exceptionally well. What were the key factors that contributed to the success of this beautiful experience?

She worked on the tree program in her department including working with the arborist. He trained her, had confidence in her abilities to assist him and answer questions for the public, and her work on the tree removal permits. He communicates effectively with her and lets her know where he is. He really trusts her and is patient explaining about any mistakes that were made.

b.) What are the key components of effective communication?

The key components of effective communication are letting the party know where you are; filling out the Outlook calendar so it is up to date; using the time out calendar which is a great tool; writing notes and leaving them on the files with the file status or project status; updating people around you on what is going on; and using good follow-up. 


\section{2.) Creating and Sustaining Positive Energy}

This organization like others is much healthier and alive when there is positive, fun energy flowing through it. When this happens the positive energy is contagious amongst the employees and the organization has a vibrant spirit.

a.) Please tell me about a time when you experienced positive energy that was infectious.

When everyone is able to communicate well with one another there is a good, positive energy flow. Without good communication there is chaos. When the information is passed on this is teamwork.

b.) What were the key factors that contributed to this energetic experience? Working with John Doe has been a positive work experience for her. He brings her a nice, little dessert treat daily. He shows he cares about her and values her. This reenergizes and lifts her spirit every day. This is a very thoughtful thing to do! She really appreciates this.

\section{3.) Respect for People}

A common theme for organizations that are recognized as great places to work is the amount of deep respect shared by the people both internally and externally to the organization. Respect is found in interpersonal relationships within departments, interdepartmentally, and across positions. There is a strong respect that is shared in the organization.

People feel respected when they are involved in conversations and decision-making, when they are listened to, when they are valued for their opinions and ideas, and when they are given the opportunity to fully participate in achieving the organization's goals. Giving and receiving respect is contagious and does not need to follow any hierarchal structure. People who feel respected in turn respect others including colleagues and customers. Some of the other by-products from respecting others are: self-confidence, enhancing teamwork, and facilitating organizational success.

a.) Please tell me about a time when you experienced a strong sense of respect from another person.

She knows that the staff she supports respects her because she gives them her full support. Respect is something that you earn. She respects the group she 
supports. It is a two-way street with both giving and taking. It is the same way that you deal with the public too. You must call them back!

b.) What were the key factors that contributed to this wonderful experience?

See the answer to question 3a.

\section{4.) Winning Teamwork}

Teamwork is an essential ingredient for success in any organization. We are individuals, but we need to effectively and openly communicate and work together to achieve common goals. In this way the organization can thrive. Individuals can also achieve so much more by working together in harmony within their work groups, in their departments, across departments, assisting customers, and in the organization in general.

a.) Please describe a time that you had seen or been a part of a team that exemplified excellent teamwork.

The excellent teamwork experience was when a co-worker went home ill. The co-worker was worried about her work. She took care of her work and the ill coworker's projects. This was a wonderful example of excellent teamwork. She saved the day and helped out when it was needed.

b.) What were the key factors that contributed to the success of this winning teamwork experience?

Think about the team and how to achieve the team goal and not the individual's goals. It does not matter how small or big the assistance is because every little step adds up to a big achievement.

\section{Conclusion}

a.) If you were given three wishes, what would your wishes be in order to enhance the health and vitality of your work group?

Three Wishes:

1.) Wishes for a City Council that would think about the City employees.

2.) Wishes that hopefully in six months that we would have a good contract for the Union employees. 
3.) Wishes that there would be more open, supportiveness to ideas (within the team) that would improve the team.

b.) If your wishes were realized and things were wonderful, what would be happening in your work group today?

There would be less complaining in the work group. It would be less chaotic in the work group. The work would get done in a timely manner.

c.) Do you have any additional comments or questions?

She appreciates the fact that she could participate in the Appreciative Inquiry process. This is a way to find areas to improve in the group.

Please take a few minutes to read through my notes to ensure I have captured the essence of your answers. Your answers will be kept confidential.

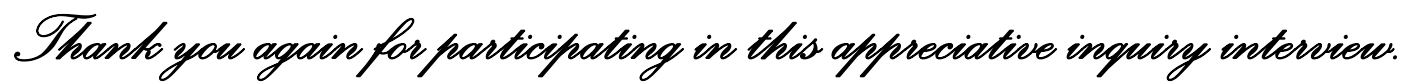


By 11/03/09, all five AI Discovery Phase interviews had been completed. The Discovery Phase positive core results were created by the team on 11/19/09. Following is the AI Discovery Phase summary from the group meetings.

\section{Summary of the Discovery Phase}

Positive Core by Focal Areas

\section{Discovery Phase Summary}

The purpose of the AI Discovery Phase was to find the positive core of the work group by using the appreciative interviews. The AI individual interviews averaged one hour in length with the five group members in the researcher's office using the AI Interview Guide. The AI Interview Guide consisted of 12 questions, including a brief introduction, two questions from each of the following sections - Opening, four Topics (focal areas): 1.) Effective/Compelling Communication; 2.) Creating and Sustaining Positive Energy; 3.) Respect for People; and 4.) Winning Teamwork; and Conclusion.

\section{Opening}

- This organization's diversity gives it life.

- This organization's culture gives it life.

- This organization's individual essence - makes it vibrant, the people in the organization and their passion for the work and services to the community and residents give it life.

\section{Effective/Compelling Communication}

- The ECS group communicates effectively by listening.

- The ECS group communicates effectively by putting themselves in the other person's shoes.

- The ECS group communicates effectively by using open and honest communication. 


\section{Creating/Sustaining Positive Energy}

- The ECS group sustains positive energy by trying to make everyone feel like they belong and are important.

- The ECS group creates positive energy by having an open and positive attitude.

- The ECS group sustains positive energy by having camaraderie (e.g., getting outside the office for a baseball game, movie night, or going out to eat at a restaurant).

\section{Respect for People}

- The ECS group respects people by going above and beyond what is expected of them when doing a job.

- The ECS group respects each other by having camaraderie and fun!

\section{Winning Teamwork}

- The ECS group has a winning team by respecting others.

- The ECS group has open and excellent communication.

\section{Conclusion - 3 Wishes for ECS Group}

- First wish, that everyone respected each other.

- Second wish, that everybody is included in the group.

- Third wish, that everyone is happy in her job. 


\section{Summary of the Dream Phase}

The next phase was the Dream Phase. The team met on 11/24/09 and developed their "Dream" in a conference room. At this meeting, there was engagement in this phase as everyone wanted to give their opinions on how to create this team's future. Following is the AI Dream Phase summary from the group meeting:

Summary of the Dream Phase

Statements of Aspiration by Focal Areas about the Ideal Way of Being

\section{Dream Phase Summary}

The Dream Phase is the second phase in the 4-D cycle. In this phase, the group is asked to envision the ideal from the themes discussed in the Discovery Phase. The group builds their future together in this phase.

\section{Effective/Compelling Communication Core Beliefs}

Theme 1: Effective/Compelling communication is clear and understandable.

Theme 2: Effective/Compelling communication maintains professionalism.

Theme 3: Effective/Compelling communication involves honesty, empathy, listening, engagement, and asks all of the right questions.

\section{Statement of Aspiration}

The ECS team maintains effective/compelling communication by being a

professional, honest, and engaging group! They recognize the importance of effective communication and they strive to continually improve their communication skills. 


\section{Creating/Sustaining Positive Energy \\ Core Beliefs}

Theme 1: Creating/Sustaining Positive Energy is done by being involved, focused, providing support to each other, and enjoying what we do.

Theme 2: Creating/Sustaining Positive Energy happens by having positive relationships with each other.

Theme 3: Creating/Sustaining Positive Energy occurs by using effective listening so people feel heard.

\section{Statement of Aspiration}

The ECS team creates and sustains positive energy by involving themselves with extra-curricular activities. They understand the importance of maintaining a work/personal life balance and having fun outside of work together.

\section{Respect for People \\ Core Beliefs}

Theme 1: A respectful team is developed by getting to know each other and by communicating frequently.

Theme 2: A respectful team is created by acknowledging each other's roles.

Theme 3: A respectful team is not arrogant and defensive. The heart of the team is based on how each team member gives and receives respect. Each team member must first respect herself.

\section{Statement of Aspiration}

The ECS team's respect for people is done by communicating frequently and acknowledging one another for who they are and what they do. The team members can gain additional respect for others by learning and having a basic understanding about each other's positions. 


\section{Winning Teamwork \\ Core Beliefs}

Theme 1: An effective team is based on support, knowledge, and skills.

Theme 2: An effective team is based on loyalty.

Theme 3: An effective team recognizes each other's achievements.

\section{Statement of Aspiration}

The ECS team has a diversity of people who share the foundational components

of winning teamwork. They are proud of the fact that they can "pull together" during a crisis. This is wonderful, but in order to have consistency and a healthy department having a daily dose of excellent teamwork would make a material difference in their department's culture and higher productivity overall. 


\section{Summary of the Design Phase}

The two Design Phase team meetings on 1/05/10 and 1/12/10 were held in the researcher's office. The office was small, but it brought the team together in a close environment which appeared to help them generate ideas on how to create the programs that would get them to their destiny.

On 01/07/10, the researcher reviewed all of the Design Programs with the Department Director and he gave his full approval to proceed on implementation. The Director was impressed with the programs that were created and he said he would help to get these programs implemented. He especially liked the Boxer’s Day and Mentoring Programs. Employees 1-5 were notified about the Director's decision. They were all enthusiastic to see their programs implemented. Some programs had more challenges than others and will take longer to implement because of interdepartmental coordination components.

Developing the dream ties directly to reality in the form of the concrete programs created in the Design Phase. A dream is usually just a dream, but in AI having a road map consisting of programs created by the team is extremely important to have sustainable goals. The team's new culture and infrastructure are made up of the implemented programs. The true power of AI as an organizational development tool and specifically in public administration is its ability to tap into the positive feelings of past events. The stories evolve into dreams and shared hopes for the future. AI is a positive approach to making changes, even small ones. Progressive Discipline was not effective with this work group. They felt harassed by their previous supervisor. AI has lifted them up along with open communication. It takes time to make changes and the ECS group is no exception. The programs that they created together will continue and this is the 
beauty of AI. How people can continue to grow both personally and professionally. Any of the positive feelings that the group had will carry on as well. Most people like to dream. Dreaming as part of a group can reenergize individuals and bring their strengths together as a collective team.

\section{Summary of the Design Phase}

Provocative Statements by Focal Areas about the New Culture and New Structures

The ECS group’s main role is to support staff in the department, as well as their other internal and external customers. This group will achieve this through their effective communication, creating and sustaining positive energy, showing and receiving respect, and using winning teamwork. The following Design Phase Summary Table Figure 6 which was created by the ECS Group shows the specific components of the new culture by focal areas which are the new values and the new structures which are the new practices, policies, and actions that need to occur to make this group’s AI dream a reality. 
Figure 6: Design Phase Summary Table

\begin{tabular}{|c|c|}
\hline Focal Areas & New Culture (Values) \\
\hline Effective Compelling Communication & $\begin{array}{ll}\text { - } & \text { Continual learning (Classes) } \\
\text { - } & \text { Excellent customer service (Cross- } \\
\text { training) }\end{array}$ \\
\hline Creating/Sustaining Positive Energy & $\begin{array}{ll}\text { - } & \text { Positive attitude (Self-confidence) } \\
\text { - Working hard/playing hard (Focus on } \\
\text { job) }\end{array}$ \\
\hline Respect for People & $\begin{array}{l}\text { Respect others for their uniqueness } \\
\text { (Diversity training) } \\
\text { - Respect others even when you do not } \\
\text { agree with them (Open mindedness) }\end{array}$ \\
\hline Winning Teamwork & $\begin{array}{l}\text { - Think team first, self second (No } \\
\text { hidden agendas) } \\
\text { - } \quad \text { Provide excellent support to all who } \\
\text { need it and especially to your team } \\
\text { members (Prioritize Your Work) }\end{array}$ \\
\hline Effective Compelling Communication & $\begin{array}{l}\text { - Work with Human Resources to add } \\
\text { additional communication-related } \\
\text { training courses (Build } \\
\text { Communication) } \\
\text { - } \quad \text { Always keep the front reception desk } \\
\text { covered and the telephone lines } \\
\text { answered. (Do Your Personal Best) } \\
\text { - Make providing excellent customer } \\
\text { service to both our internal and } \\
\text { external users the number one priority. } \\
\text { (Focus on Customer Service) }\end{array}$ \\
\hline Creating/Sustaining Positive Energy & $\begin{array}{l}\text { - Team members regular planning of } \\
\text { extracurricular events (Plan for Fun) } \\
\text { Engage our colleagues with small } \\
\text { surprises - like having consistent moods } \\
\text { and acknowledging each other's presence. } \\
\text { (Awareness) }\end{array}$ \\
\hline Respect for People & $\begin{array}{l}\text { - Team members automatically giving } \\
\text { other employees respect (Self-esteem) } \\
\text { - } \quad \text { Team members giving other employees } \\
\text { the benefit of the doubt (Self-esteem) }\end{array}$ \\
\hline Winning Teamwork & $\begin{array}{l}\text { - Team members thinking and acting like a } \\
\text { team. First, do what is best for the team } \\
\text { and the department. (Generating } \\
\text { Goodwill) } \\
\text { - Team members doing their personal best } \\
\text { in the office on a daily basis as well as } \\
\text { well as being extremely productive in } \\
\text { their work. (Strong Work Ethic) }\end{array}$ \\
\hline
\end{tabular}




\section{Summary of the Destiny Phase}

Programs to Implement by Focal Areas to build the New Culture and New Structures

The researcher facilitated discussions with the research group members to develop programs along with their approximate timetable for implementation, which is at the end of each component. Each team member identified and took full responsibility for researching one program to implement. They brought back their program information to the group and were working on implementing their programs with the help of the researcher and other group members. All of the Design Programs were reviewed and approved by the Department Director prior to the group implementing them. They were also supported by the other upper levels of management.

\section{Focal Area: Effective/Compelling Communication}

\section{Classes - Staff-1}

Due to the economic downturn, the organization's training program has been downsized to only a few classes being offered. This first program would involve offering communication and listening skills classes using CD’s and/or Videotapes. The first CD class that was offered was by Dr. Cherie Carter-Scott's Overcoming Negativity in the Workplace and a future one may be Stephen Covey's, The Seven Habits of Highly Effective People. These classes would instruct on how to understand different communication styles and the most effective ways to deal with both internal and external customers. The implementation of these classes would take up to three months, but the goal was to have offer a class once a quarter, eventually having live instructors teaching the courses. 


\section{Focal Area: Creating/Sustaining Positive Energy}

Excursion/Trips - Employee 5

A major theme from the Discovery Phase was having fun and getting to know each other in a more casual setting. This program will involve a local excursion/trip. This would involve a meal and then movie or other form of entertainment away from the office. The premise is that more informal interaction between members of the group will provide them more insight/understanding of their fellow workers and strengthen the bond between them. These excursion/trips would be planned for after work to occur once every three months.

Retreats - Employee 5

This program would involve the group having a working retreat away from the office. It would take place during office hours either for a half or full day. There would be a formal agenda on topics to cover with an overall goal from the experience. Venues could be other organizational facilities or parks. This would give the team the opportunity to meet without interruption and focus on their core functions as individuals and as a group. Due to the continuing economic challenges, the group would not receive any budget dollars and would borrow a city facility room for a half day retreat. Most likely the team would bring brown bag lunches. These retreats would occur once or twice a year.

\section{Focal Area: Respect for People}

Boxer's Day/Role Play - Employee 2

This training program would involve temporary, voluntary job switching within the organizational department. The goal would be to provide insight to all of the 
departmental employees who participate in doing other job roles. It would be an invaluable experience to "put oneself in another person’s job” for a finite period of time. The objectives are cross-training, increased understanding of the unique and important roles that each departmental employee plays within the organization, and input from participants on ways to improve current processes. The group did not thoroughly discuss the challenges in getting others to participate in this exercise. There was more focus on this group then the outside group. There was the feeling that others within the department would want to participate. There were not any discussions regarding Union issues because there were two Union departmental stewards in this group. The Union stewards usually are right on anyone who tries to do anything differently, but in this instance they did not mind since they both were members of this work group. The implementation would be zero to twelve months.

\section{Job Shadowing - Employee 2}

This training program involves observing an employee doing his regular job tasks along with verbally explaining what he is doing to the shadowing employee. This will give the employee, who is job shadowing, additional understanding of that particular job. The outcome will be more awareness and understanding of other employees’ job responsibilities. The benefits that could be attained from participating in the job shadowing outweighed the costs. There was some uncooperative behavior from a couple members of the group when the job shadowing was being planned. It was brought to the researcher's attention and it was beyond the scope of the research project to address the poor behavior. This program would be implemented in zero to twelve months. 


\section{Focal Area: Winning Teamwork}

\section{Swap Jobs with Other Departments - Employee 3}

This program consists of interested employees in the department temporarily swapping jobs with other departments' employees who would voluntarily participate. The outcome would be increased relationship-building and understanding of other departmental processes. This would strengthen the departmental bonds between employees as well as communication and understanding of other departmental processes. In the planning stage, there was discussion about what other departments would want to participate in swapping jobs. What ended up happening was that there was some initial interest by a new employee in another department, but then her supervisor said she could not participate. Implementation would be between three to six months.

\section{Mentoring Program - Employee 4}

This program will consist of matching mentors with mentees within the department. Mentors need to have the willingness to help the mentees find the resources to help them achieve their career goals. The mentees need to be motivated to actively work with their mentors and implement their advice to work toward their career goals. This is probably the most critical program that needs to be implemented, but it was not a priority for the person who signed up to coordinate it. There was strong buy-in from the Department Director for this program. The researcher did need to continually follow-up with employee 4 regarding this program to move it toward implementation. This program was in the process of matching the mentees with the mentors. There were only five interested mentors, but then this program was going to be a pilot program for the five interested ECS team members. If this program were successful, then it would be opened 
up to the rest of the department. The implementation of this pilot program would be between zero and nine months.

A class and four excursions/trips have already occurred as part of the Destiny Phase. These employees had years of resentment built up in themselves and they felt manipulated by the system on a daily basis. Some of them even commented that they felt they were in prison when they were at work. By taking control and responsibility for at least one program from design to implementation it empowered them. It was amazing for the researcher to witness how employee 5 has changed her attitude not only regarding her work, but also about Union issues. The researcher has seen a strong change in employee 5's behavior. The key to this group is about listening to them and making them a part of developing the dream. The dream is really about the employees feeling better about themselves. Each time employee 5 organizes a dinner/movie night the dividends to her were increased self-esteem. There was a direct correlation between the Dream Phase and the reality of actually implementing a program. Providing an employee the responsibility of creating, planning, and coordinating an event was an opportunity that some of them had never experienced. The team members received positive recognition and it gave them a sense of ownership. Instead of the support staff team members complaining about other employees, they can lead them in an event and they can also deal with others who may complain to them if they are not satisfied. The team members began to understand how negative complaining/whining was and how it felt to do something positive. Some of them apologized to the researcher for their bad behavior that they had expressed to her over the past several months.

Employee 5 was a shining example of the effectiveness of the AI process. The AI literature says a person must be open to having a positive change for one to happen. 


\section{Summary Findings}

The findings from this case study are in this section. Each issue was stated and reinforced by the relevant literature review component.

The researcher observed a variety of unacceptable behaviors during the AI process. There were some behavioral issues in this group. Some group members were not consistent with their moods, decided not to talk with other team members and became actively disengaged, and these behaviors were disruptive to the team. There were also some strong anger issues that surfaced from time to time in the group as well as to other department members.

In the literature review, Greenberger \& Padesky (1995), presented a diagram that showed how there can be a chain reaction on mood based on thoughts, then this causes behaviors, and turns into physical reactions. These changes can also affect the environment. In the Anger Profile Table also by Greenberger \& Padesky, it had a description for the four reactions. The researcher thought these basic concepts were important to understand because it makes us more aware of the physical and mental reactions of others.

This situation must also be looked at from the researcher/supervisor's point of view. There were certain group members who would not follow even the basic rules, who were always trying to find a loop hole in any process. Such employees wasted countless hours on trying to persuade their supervisor that something was not fair, or that no one else had to follow the procedure or rule, making it unfair to have imposed that rule or procedure on them. It was a constant, irrational struggle for no productive purpose or outcome. One employee even went so far as to poll other employees on two floors about a Payroll policy involving timecard coding that she thought was invasive of her personal 
business. She became very angry and confronted the Payroll Manager about the payroll policy. The researcher also observed other inappropriate anger issues from the group members.

In the past, this group did not know what boundaries were or they chose not to follow them. The literature review had some information from Whitney, et al. (2004), in Appreciative Team Building: Positive Questions to Bring Out the Best of Your Team, which discussed "achieving a productive balance” and also provided eight dimensions for effective teams.

Each team member in this study did have great communication skills. They were able to communicate very effectively verbally especially when they were trying to persuade the researcher on something they thought was best for themselves and/or the team. An area that most of them had difficulty in was hearing and taking in constructive feedback on their performances. They had the perception that they were "perfect," even though their behavior to both internal and external customers, was often below expectations. In order for these team members to move up in the organization, they would need to be able to really listen to constructive criticism about their performance and modify their behaviors accordingly. Awareness was just the first of many critical steps that they needed to take. Accountability and responsibility were important in order to make them more effective team members.

In Covey (1989), The Seven Habits of Highly Effective People book, he laid out the seven habits in order to be an effective person. He also explained the emotional bank theory which was a very powerful one showing how we need to trust each other. Covey also explained that the most important deposit was the understanding of the individual. This book and its concepts were extremely proactive and positive, too, and would be a 
good book to recommend to the group members to read and for the researcher to apply the habits.

Another area that was problematic was the relationship of the team members to the Union and to the organization. It was important for the team members to understand who provided their employment, including their paychecks. The team members were divided in their loyalty to the organization and to the Union. Last year, the organization had twenty-six negotiating sessions over five months. This was with the Union that represented these five team members along with almost six hundred other employees. The most contentious issue was that the organization was facing economic challenges due to a recession and it needed to reduce the benefits of its employees to counterbalance the loss of significant revenues (e.g., Sales Tax). The Union was not happy with how the negotiations were proceeding so they had a "Sick Out Day" and another "Volunteer Day.” The "Volunteer Day” was an unofficial strike day. The Union members were expected to call in sick or not call in at all for the Volunteer Day. Basically, the Union was trying to show the organizational officials and the residents that they could cripple the organization by not having their Union members show up for work. The organization was able to continue most functions on these days and this sent a strong message back to the Union that they could not significantly interrupt the organization's operations. There were team members who were conflicted about participating in these Union-sponsored days. One or two of them still came into the office to work even under extreme peer pressure.

In Managing Change At Work, Scott \& Jaffe (1995), under the Communication section of Literature Review, their emphasis was on communicating before, during, and after the change(s). They said it was also necessary to share the basic goals of the 
organization with the people in it, as well as communicate clearly to them. This will help to lessen any negative impacts of the change.

The AI Discovery process began toward the end of the Union negotiations when there were rumors of an impending big strike. Emotions were high amongst the group, combined with extremely low morale. A conscious decision was made by the researcher to start the Discovery Phase in hopes that there could be some positive feelings in this group from the AI process. The outcome was that the researcher did see a temporary, positive shift in the group's morale; even though there was still anxiety in the group members over the labor negotiation's outcome.

In Appreciative Organization by Anderson, et al. (2008), he discussed the six results that often time occur when valuing is important. If the group members felt valued perhaps they would have more value in themselves, they would have more self-esteem and respect for who they are.

During the Destiny Phase, the researcher asked the group if any of them had anything to share regarding their AI experience. They all agreed that telling stories in the Discovery Phase was nice for reflection and it brought back positive memories. Some felt like it was just the same as the other organizational development tools that they had experienced. They also would like to have seen other groups in the organization trying it first. One member commented that it was just one more "trial and error" thing for them to do and "Here we go again!” They also commented that there was a morale factor involved with the economy being so bad, the organization and the Union negotiations, and them being on the bottom of the totem pole. Another thing they would like to have addressed is the morale issues (the elephant in the room) by having a dialogue between the various sections of the department. 
In Reed (2007), Appreciative Inquiry: Research For Change noted that:

“Appreciative Inquiry focuses on supporting people getting together to tell stories of positive development in their work that they can build on” (p.42). The Discovery Phase was one of the highlights for the ECS Group members in the AI process. Why was this? This was because they had someone who listened to them very intently and was interested in hearing their stories.

The true essence of the AI positive core was really about the organization valuing people and relationships. Everything else flowed from there. In the past, this group did not think that anyone was listening or valued them, so they started to act up over the years, which contributed to the dysfunction in their group. They did not follow any of the six norms previously mentioned in the literature review. Unfortunately, they had gotten to the point where they needed to find a new job somewhere else, either in the organization or outside of it. They had years of resentment built up, not only for their group members, but outside their group as well. A new functional environment would give them the opportunity to have a chance to work towards their career goals. Their current work environment will remain dysfunctional as long as the five members do not take responsibility and are not committed to changing themselves.

In The Power of Appreciative Inquiry: A Practical Guide to Positive Change by Whitney \& Trosten-Bloom (2002), it listed the Eight Principles of Appreciative Inquiry. These eight principles were very powerful containing the AI beliefs and values. Unfortunately, no one can change another person, and especially their values. Instead, guiding someone to helpful resources and modeling behaviors can assist the people who wanted to change. 
The AI experience allowed the team members to work in a positive way to try and build a positive future together. The AI programs that the ECS group created and implemented will reinforce what they learned in their AI experience. The AI allowed them to broaden their horizons and to communicate more effectively with each other. The researcher on many occasions would remind the group members that it was okay to not agree with someone in a meeting or in any other setting, but they do not need to try and change the other person's beliefs. Everyone has a right to their opinion and to be heard in a respectful way. The AI theory, with its four phases, provided these group members with an alternative change option as opposed to the progressive discipline that they received heavy doses of in the previous five years. Employee 5 spoke to the researcher one day in her office. She remarked that the researcher had a "nice strength" in her supervisory style as opposed to the previous supervisor who was always disciplining the work group.

\section{Characteristics of Effective Teams}

The team in this case study was effective at certain “crisis” times, but they could not sustain this performance.

What characteristics does an effective team need to have? In the literature review, there was an excerpt from Cheney (2004), et al. in Organizational Communication in an Age of Globalization. There was a study done by Larson and LaFasto which defined the characteristics of an effective team. The main elements were a clear and challenging goal; a unified commitment by the team; a results-driven structure; collaboration; competent team members; standards of excellence; external support and recognition; and principled leadership. 


\section{Analysis}

This analysis section consists of the case analysis and the survey results.

\section{Case Analysis}

As stated earlier, this case study was about an established group of people in a work group in a department. It was done to see if there were any qualitative benefits to this team and department from applying the AI principles. This case analysis section will systematically chronicle this case process and provide the outcomes of each of the four phases - Discovery, Dream, Design, and Destiny.

The researcher created an AI interview guide using the Encyclopedia of Positive Questions - Volume One - Using Appreciative Inquiry to Bring Out the Best in Your Organization. The topics chosen were Effective/Compelling Communication; Creating/Sustaining Positive Energy; Respect for People; and Winning Teamwork.

During the five interviews which were held in the researcher's office from 10/2111/03/09, there was initial nervousness by both the participants and the researcher while they signed their releases, but once the opening questions were asked the researcher could tell that the subjects sat back and relaxed as they focused on telling their stories and so did the researcher. There had been a reoccurring theme in the past six months that this group had not been listened to in the past and that they felt their opinions were undervalued. The AI Discovery process gave them a chance to have one-on-one time with the researcher to bond and share some of their experiences. They appeared to enjoy the positive questions and a few of them commented that in our society today there is so much negativity that they enjoyed looking at positive things for a change.

After the Discovery Phase, the researcher spoke with her advisor about the past bad behavior of most of the group members. The advisor suggested she try a Personal 
Discovery (Appendix J) experience using the Power Point program. It needs to be noted that each of the women in this group had low self-esteem and for whatever reason felt undervalued. One of the women was passive, the rest liked to verbally attack whenever they felt insecure or threatened. The Personal Discovery experience occurred in one meeting on 11/10/09. They all seemed to enjoy it and they shared whatever they felt comfortable discussing about themselves with the group. The researcher provided a template that described her as a scholar, wife, mother, daughter, etc... She also put down what a typical day was like for her. There was engagement and participation by the group in a positive way. It appeared that they really enjoyed the personal discovery exercise. One of them commented to the researcher later that she really liked doing it. This group wanted to learn and most of them really wanted to move up in the organization.

There were several sessions with the whole group from 11/10/09-02/12/10 to find the Discovery Phase themes and the positive core; then the Dream of what might be for the group; the Design Phase crafted the provocative and inspiring statements of intention; and finally the Destiny Phase where the programs were created to fulfill the group’s future. Throughout these meetings, the researcher was amazed at how this group came together and worked as a team to supply the needed answers. Although their answers did not match their behavior, it was almost surreal listening to them. It is important to note that a few of these meetings were in conference rooms, but the meetings that had the most engagement were the ones in the researcher's office. There were six people in a small office with a white board, which included one volunteer scribe. When asked, "They said it was a little cozy in the small office.” Yet there was a feeling not only of physical closeness, but emotional closeness as well, as observed by the researcher. There was 
additional team camaraderie that had never been displayed to the researcher before. They were respectful towards each other yet honest and they communicated how they felt throughout the process to the researcher and the group. At times, they almost appeared to be enjoying the AI experience, especially during the Design Phase. Towards the end of the AI process in both the Design and Destiny Phases employee 4 became disengaged. Perhaps she was bored. She would stare off out into space. In order not to embarrass her, the researcher played a passive role while her team members encouraged her to participate in the Design Phase by selecting a program to coordinate. This employee tends to have fairly regular mood swings which tend to upset her group members. The researcher was impressed at how the team was able to engage another team member while they were all involved in the AI process.

It was the researcher's observations and also the group’s verbal confirmation that they wanted to be part of the decision making process and not have policies and procedures just dropped on them. They wanted to be informed about what was occurring in the rest of the department and in the organization. They wanted to be treated "fairly," meaning the same as all of the other positions in the department. There were times when they used depreciating language about themselves (e.g., they called themselves the bottom feeders and dysfunctional). The researcher always tried to be open and allow them to have input in the decision making process. She had been open regarding the budget challenges so that they could be more knowledgeable about them.

The Destiny Phase was one that the group especially enjoyed because they each were able to take responsibility for one of the programs to be implemented. They did the research and brought it back to the group. They were actively engaged and liked taking ownership of a program. 
One of the most powerful programs to be implemented for this group was a Mentoring Program. The reason this program would be helpful was that the average length of time in this department for these women was nine years with minimal turnover. Most of them thought they were ready to move up in the organization. The researcher felt it would be very beneficial for them to have a mentor/coach who was not their manager to give them tips on resources and activities they could do to achieve their goals. If this program were set-up correctly it would be an Appreciative Coaching program. In the literature review section, Orem, et al. (2007) in Appreciative Coaching: A Positive Process For Change maps out the four questions that would be asked at the first AI coaching session. The answers to the four questions would provide valuable feedback about the person to the mentor and also allow the mentee to positively think about how her life is now and what she would like more of in it. This time for reflection has been good for this group as they progressed through the AI phases.

The next logical step for the group members was to find a coach/mentor and work on mapping out their positive career.

Whitney, et al. (2004), Appreciative Team Building: Positive Questions to Bring Out the Best Of Your Team the other AI goals included:

"Aligning the strengths of the team members; building camaraderie and trust; establishing team norms; celebrating team successes; clarifying both internal and external customer requirements; aligning the strengths in the face of cultural differences; creating the overall team vision and goals; creating a team identity and enhancing pride; and energizing team meetings” (pp. 10-15).

The researcher worked with the team on the aforementioned nine goals. She worked extensively with the team members on recognizing their strengths in a team 
meeting and in one-on-one meetings with them. In order to build camaraderie and trust and also to celebrate successes, the researcher organized a lunch on 10/01/09 at a local restaurant for the team and on 12/09/09 she took them on a field trip to one of the large projects that most of them had provided support on. They appeared to enjoy both of these outings. On another day she also took a subset of the group for a walk to a local park where they had their brown bag lunches. On a different day she took out one team member for yogurt because the Director said that the employee had done a great job on a project. The next outing was to treat the group to coffee or tea at a local café which was supposed to be part of the researcher's team meeting.

The researcher received positive feedback on the work group from other departmental members regarding their attitudes and overall work performance. The team meeting was held in the researcher's office. At the end of the meeting some of the team members did not want to go and get treated to tea or coffee. Out of the five team members only employees 1 and 5 went with the researcher. They both commented as they were walking on the way to the coffee shop and back that they would go anytime there was something “free.” The researcher was initially surprised by these comments, but then quickly realized that this is their mentality and unfortunately both of their interpersonal skills were lacking. Establishing team norms was a work in progress as well as clarifying both internal and external customer requirements; aligning the strengths in the face of cultural differences; creating the overall team vision and goals; creating a team identity and enhancing pride; and energizing team meetings. The researcher did develop the ECS Staff Procedures in January 2010 (Appendix K). The group reviewed and agreed upon the procedures. After watching the video on Overcoming Negativity in 
the Workplace, employee 1 created an ECS Team Contract (Appendix L) that was signed by all five team members. Both of these items added additional structure to the team.

There were strong cultural differences in this group. The thread that will bring them together in the future is learning about and understanding their cultural differences. They also need to learn more about themselves. Once they have more self-esteem and appreciation for their differences they will be better equipped to work together as an effective team. During this AI process, the researcher discovered on several occasions, members of the team trying to manipulate her into making quick decisions that would mainly benefit themselves and not the rest of the team or department. If their wishes did not become reality, then they would retreat only to think up another request or two to ask the researcher. This was an ongoing, one-sided game. Different team members also spent time with the researcher before and at the beginning of the AI process telling her negative comments about other team members. As the AI process continued, this type of negativity started to diminish. The researcher attributes this to the various AI sessions where these team members opened up and discussed how they felt about certain teamrelated issues.

It is interesting to note that more than one time during the last six months other employees from outside the department commented to the researcher that the team members had a "heart of gold," but they were just very strong, demanding women. These people also said they felt sorry for the researcher having to be their manager. The researcher appreciated that the employees "had a heart of gold,” but they also must learn to use proper etiquette in the office and take responsibility for their actions. If they truly want to move up in the organization, they could still maintain their individuality, but they all needed to focus on their jobs. Some other areas were: to minimize comparing 
themselves with others, stop worrying about everyone else's work schedule, do their jobs the best that they can, learn as much as they can, offer to help others above and beyond the minimal level, ask for special projects when they were low on work, maintain a consistent and pleasant demeanor when in the office, follow the basic office rules, volunteer for extra projects, find a good mentor/coach and implement their advice, be mindful of other employees’ time, and provide excellent customer service.

There had been unsolicited feedback, from some department employees, after the post-intervention surveys were completed. These employees complimented the researcher and told her that they had seen a positive change in the ECS support staff group.

\section{Surveys Results}

There were pre- and post-intervention surveys, the actual AI process, and the behaviors noted by the researcher pre-, during, and post-AI intervention process. All of this qualitative material provided information on whether these five employees had become a stronger team.

On 9/30/09, a pre-intervention survey was given to the Other Key Staff with the results in (Appendix F) and to the ECS Staff with the results in (Appendix C). The ECS Staff survey used the SurveyMonkey instrument and the Other Key Staff who received frequent support from the ECS Staff members. The Other Key Staff were given a hard copy of the survey. The AI 4-D cycle experience next occurred between 10/20/0902/12/10 and then a post-intervention survey for the Other Key Staff Survey and Results (Appendix G) and the ECS Staff Survey and Results (Appendix D) were both distributed on 02/16/10 using the SurveyMonkey instrument. Both of these surveys results were kept confidential by not showing any staff names. The pre- and post-intervention surveys 
response for the ECS Staff was 100 percent. The Other Key Staff pre-intervention survey response was 48 percent and the post-intervention survey response was 63 percent.

The ECS Staff survey results showed a willingness of this team to try and work together. They understood how important communication and supporting each other was to getting the job done. Overall, they enjoyed being part of a team and the majority believed they were perceived as leaders and were leaders in their own unique way. When asked what they learned from participating in the AI experience, there were a variety of answers. Employee 1 wrote, "It was beneficial because it brought everyone together to achieve a goal of improving our team.” Employee 4 wrote, “We are all different opinions, outlook, goals, styles, values, principles, but we have the same basic needs respect, flexibility and the desire to be ourselves.” When asked if they thought other groups might benefit from the AI experience the majority felt it would be good for the other work groups. When the researcher asked the final survey question about any additional comments/suggestions employee 2 responded, "Even if people are resistant to the program, they will be forced to see where improvement could be made, and will discover practical steps to improving the team. This could be an eye-opening exercise for everyone.”

The whole AI experience was an eye-opening exercise for the researcher. She had participated in an AI experience with her Communication Studies class team at The Tech Museum of Innovation. Due to time constraints, only the Discovery Phase was done interactively with some of The Tech Museum employees. There were questions asked after the Discovery Phase about the Dream, Design, and Destiny Phases. Later the class team developed the rest of the phases and their outcomes together. In contrast, this 
work group’s AI experience allowed the researcher to really hear the participant's stories and also to walk through the AI experience with the rest of the team.

The results of the Other Key Staff post-intervention survey highlighted what key members of the department thought of their support team. In reference to the level of quality of service received, the department highlighted the first question asked which was, if they were satisfied with their support staff person. One respondent wrote, “The key word is "support" - not that I am so busy I cannot be interrupted by anyone today.” Most of the respondents said they were satisfied with their support person. When asked what were the team's strengths the participants replied that they were hard working and willing to help. Another replied, “There seems to be a lot of cross knowledge between them, but they also tend to run very hot and cold with each other.” When asked if the participants saw any positive changes in the support staff team in the past six months, the responses were split. There were five definitive no’s and five positive responses. For example, one participant wrote, “They generally seem to be more supportive, friendly, and willing to do what is needed to help out.” Another wrote, "Better clarification on who is responsible for what task and being able to go to any staff member for help.” Final suggestions/comments from a participant were "Keep trying and working hard." Another suggestion was, “I feel that I don't know the complete scope of services that our support staff can, or are responsible for providing. A list of "what your support staff person can do for you” would be helpful. I do not always know what is appropriate to ask them and feel like I could be utilizing them more.” Respondents to the Other Key Staff surveys were able to provide constructive feedback regarding their support team. The researcher shared this feedback with the team. When the researcher shared the Other Key Staff survey responses she suggested that the team could create a list of "ordinary" 
items they do. All five members of the ECS team rejected this helpful idea. The Other Key Staff surveys provided some tangible areas for improvement and this was a gift to the ECS team. Overall, there was some perceived improvement areas from both the ECS group and the Other Key Staff members. The AI experience was helpful in bringing this group together and helping them to discover their strengths. This was only the beginning of the road for them. The ECS group could be a strong team, but they do have some work ahead of them to make this a reality.

The researcher saw some positive progress in the ECS group after the application of the AI process. There was still a lot of work that needed to be done to bring up the work and maturity level of this group. Their dysfunction did not occur overnight and it will take more than one AI process to turn them around, but the researcher remains hopeful for the future. If the AI principles were consistently applied to this group, they might decide to modify their attitudes and behavior and work toward creating their ideal office environment.

In summary, the AI theory was applied in a local government organizational department to a five women work group whose core function was to provide support excellent customer service to their sections. Positive results had been perceived in a small way. A conscious decision must be made by the individuals in this work group to change. Until then no organizational development tool will have miraculous results on their behavior or work productivity. They needed to start feeling better about themselves so they could focus on their communication, teamwork, and leadership skills. Employees 1-5 each had strengths and areas for improvement. Some of their strengths really stood out, especially during the appreciative inquiry experience. What was lacking in this AI process? It was a true commitment, by each of the participants, to take responsibility for 
their strengths and areas for improvement, to really trust each other, and to be loyal to the team. Even after the AI Discovery, Dream, and Design processes officially ended in late March 2010, there were team members that would send the researcher emails about their other team members' lateness or other behavioral items. This demonstrated a lack of loyalty to the team and also in using communication, because they could have addressed these issues themselves or really worked together as a team to set examples and make each other conform. 


\section{Lessons Learned}

This section includes change item insights that the researcher gained during the AI research process. The first change item would have been to present AI in a different way, basically keeping it simple and explaining during the introductory meeting that the project was for the researcher/manager's Master’s Degree Program research paper. The researcher also would have made AI handouts and a link to the main AI web site and given the potential participants the handouts in advance, so they had time to read them and formulate their questions. This would have potentially allowed for a calm, positive discussion of AI instead of the negative one that occurred. The initial response to AI laid a foundation of negativity which could have been a positive one if the information had been presented differently. Conversely, presenting any information to this group, no matter how it was presented, would most likely upset them. They had extremely low self-esteem and non-existent self-worth so they would have rebelled with any type of AI information presentation. The bottom-line was they wanted to be in control and disliked any surprises.

Secondly, due to the uncertain nature of some of the participants, the researcher chose to select the topic and the focal areas for the AI. In retrospect, this could have been structured to reinforce the buy-in of the group and provide them with a feeling of empowerment. Also, the researcher asked the appreciative questions in a one-on-one session where it would have been beneficial to have had at least one other team member present to ask the questions and benefit from hearing the responses and vice-versa. It most likely would have been too overwhelming to ask one person in the group to answer their questions in front of the whole group. Conversely, there are issues of confidentiality 
that might have arisen, and the opportunity for the one-on-one experience with the individual team members may have established a good base for future conversations.

The third item would have been to have a one to two day off-site retreat to do the AI process as opposed to stretching out the AI over almost three months. This would have allowed the researcher and the participants to fully focus on the AI experience and leave the office distractions behind temporarily. The ability to do each phase, one after the other, would allow for a continuity that did not occur due to the large span of time between some of the phases. There also would have been more bonding between the team members and the researcher in an off-site setting. Conversely, spreading the phases over time may have been beneficial in providing time for reflection, and providing a sense of evolution from one phase to the next rather than a time sensitive and structured approach.

The final potential change would have been to include other sections of the department in the AI experience, not as part of this group, but to have various AI processes occurring simultaneously. This would have been more meaningful to this group if another group or groups in the department were also participating. Certain members of the group labeled themselves "guinea pigs," which the researcher took as a negative comment. When this reference was brought up the researcher tried to turn it into a positive by letting the group know that they were doing a groundbreaking experience. This was something other organizational groups may be able to do if this group were open to a positive change in their professional and/or personal lives.

In organizations today, there are a lot of taboo subjects, especially when it comes to naming the elephant in the room. It is important that different people's perceptions of this elephant are brought to the surface. Organizations would benefit from having a 
constructive dialogue. This five member group would learn so much by being able to participate in constructive dialogue and it would minimize counterproductive time spent on trivial subjects. The researcher has worked with them on meeting etiquette, including waiting for the meeting leader to acknowledge a person before they start to speak, and to not interrupt the person who is speaking. There have been times when there were shouting matches to make a point in a meeting. The researcher tried to maintain meetings that were friendly in nature and that relayed information that would help to get the job done more efficiently. 


\section{Conclusion}

This applied research project provided the researcher an opportunity to learn much more about the AI theory and to apply the skills acquired from participating in San José State University’s MPA program. The goal was to both enhance the effectiveness of the manager, but also to make a significant difference in the work environment of the participants. These goals were partially achieved in this AI research process. It will take additional months to further enhance the effectiveness of the manager and to significantly make a difference in the work environment. The foundation has been laid for both of these items, but it will take time, consistency, and further outreach to the team to make additional progress in these areas.

AI theory suggests that the key to success is building upon existing strengths and helping others to see their strengths and how they can individually contribute to the collective team effort. The AI theory has been applied and it will take the commitment of the team members and their manager/researcher to fully implement the programs of the Design Phase to make their dreams come true. AI can be a powerful tool in both professional and personal lives, but it takes a deep personal commitment and persistence to attain the desired goals. Also, if AI were applied in the whole organization it could be especially effective due to the interactions amongst the various sections of the organization, not just an extremely small subset of the organization participating in this change effort. AI is a powerful, positive paradigm shift that can have remarkable results as long as the participants are open to making this change.

The AI theory has proven in research to make a paradigm shift from negative to positive. Focusing on strengths can build a stronger tomorrow for individuals, work 
groups, organizations, communities, and society. There is hope to fulfill a much bigger dream with the consistent application of Appreciative Inquiry.

Would the AI experience be good for more than just five members of a department in this organization? First, the amount of time that was spent on the AI was not that significant, approximately 40 hours in total. Second, the economy was still in a recession that was headed toward a depression. Third, this organization, like many others, was retrenching with another year of layoffs. This would not be a good time to do the AI process organization-wide at this city government. In 2000, this organization brought in the Gallup organization to do a Q12 telephone survey. This initial Q12 survey consisted of 12 questions to gauge the engagement of the employees. The survey was done in 2000 with a follow-up survey in 2002. Over \$1 million dollars was spent on these surveys and their results. The survey results showed quite a few disengaged employees, some engaged, and others that were highly engaged. The follow-up work for the Q12 that was done was not effective because the commitment factor was not present in the employees. This same commitment factor would also be missing in an AI process at this city, especially since morale is at its lowest. The reality is that many employees in this organization were fixated on what they thought they were "entitled" to have in their employment. Also, with a highly charged Union environment in this organization it would be challenging to actually get the AI process approved. Conversely, the researcher would not close the door on an organization-wide AI, but it may be helpful to wait a few years for these items to rebound so that the employees are in a more appreciative mood.

It is important to find innovative ways to create the preferred future. Bernard J. Mohr (1999) was originally on the AI Listserv. He was also published in Appreciative Inquiry: Change at the Speed of Imagination by Watkins \& Mohr (2001). He expressed 
something that the researcher believed as well: "When organizations are designed to allow members to find meaning, dignity, and community in their day-to-day lives, the benefits to society, the company, and the individuals are enormous. Unless we are engaged in helping people to redesign their sociotechnical architecture in alignment with their dream, I think we are missing a great opportunity and may even be derelict in our responsibility” (Watkins and Mohr, p. 151).

In Cooperrider \& Whitney’s (1999) book, Appreciative Inquiry - Collaborating for Change, the following paragraph sums up the AI experience:

"Perhaps our inquiry must become the positive revolution we want to see in the world. Albert Einstein's words clearly compel: There are only two ways to live your life. One is as though nothing is a miracle. The other is as though everything is a miracle” (p. 29).

The researcher believed in miracles when she did this case study. Employees 1-5 and the researcher all had to be open to positive changes. Employee 5 was open to change and she truly experienced the powers of AI. As a result of this Appreciative Inquiry, the researcher’s life has changed too in positive ways. 


\section{References}

Anderson, H., Cooperrider, D., Gergen, K., Gergen, M., McNamee, S., Watkins, J., \& Whitney, D. (2008). Appreciative Organization. Chagrin Falls: A Taos Institute Publication.

Barrett, F., \& Fry, R. (2005). Appreciative Inquiry: A Positive Approach to Building Cooperative Capacity. Aptos: Taos Institute Publications.

Berube, M., et al. (2002). The American Heritage College Dictionary - Fourth Edition. Boston: Houghton Mifflin Company.

Bushe, G. (1998). Appreciative Inquiry with Teams, The Organizational Development Journal, 16:3. 41-50.

Cheney, G., Christensen, L., Zorn, Jr., T. \& Ganesh, S. (2004). Organizational Communication in an Age of Globalization. Long Grove: Waveland Press, Inc.

Cooperrider, D., Sorenson, P., Whitney, D., \& Yaeger, T. (2000). Appreciative Inquiry: Rethinking Human Organizations Toward a Positive Theory of Change. Champaign: Stipes Publishing, LLC.

Cooperrider, D., \& Whitney, D. (1999). Appreciative Inquiry: Collaborating for Change. San Francisco: Berrett-Koehler Communications, Inc.

Cooperrider, D., \& Whitney, D. (2005). Appreciative Inquiry: A Positive Revolution In Change. San Francisco: Berrett-Koehler Communications, Inc.

Cooperrider, D., Whitney, D., \& Stavros, J. (2003). Appreciative Inquiry Handbook - The First in a Series of AI Workbooks for Leaders of Change and CD. Bedford Heights: Lakeshore Publishers.

Cooperrider, D., Whitney, D., \& Stavros, J. (2008). Appreciative Inquiry Handbook - For Leaders of Change $/ 2^{\text {nd }}$ Edition. Brunswick: Crown Custom Publishing, Inc.

Covey, S. (1989). The 7 Habits of Highly Effective People. New York: Simon \& Schuster.

Greenberger, D., \& Padesky, C. (1995). Mind Over Mood: Change How You Feel by Changing the Way You Think. New York: The Guilford Press.

Hammond, S., \& Mayfield, B. (2004). The Thin Book of Naming Elephants. Bend: Thin Book Publishing Company.

Horton, S. \& Hondeghem, A. (2006). Public Service Motivation and Commitment, Public Policy and Administration,Vol. 21. 1-12. 
LaFevor, K. (1999). A Dissertation on the Effectives of Employee Disciplinary Processes A Comparison of Progressive versus Positive Disciplinary Models. Florida: University of Sarasota.

Law, E. (1993). The Wolf Shall Dwell with the Lamb. Danvers: Chalice Press.

Luton, L. (2005). Why Qualitative Research Is Important in the Public Administration Research Tradition. ASPA Conference in Milwaukee, Wisconsin: 4/4/05.

Orem, S., Binkert, J., \& Clancy, A. (2007). Appreciative Coaching: A Positive Process for Change. San Francisco: Jossey-Bass.

Pincus, M. (2004). Managing Difficult People: A Survival Guide for Handling Any Employee. Avon: F+W Publications, Inc.

Preskill, H., \& Catsambas, T. (2006). Reframing Evaluation Through Appreciative Inquiry. Thousand Oaks: Sage Publications, Inc.

Raynes, B., (2001). Predicting Difficult Employees: The Relationship between Vocational Interests, Self-esteem, and Problem Communication Styles. Applied H.R.M. (Human Resources Research)

Reed, J. (2007). Appreciative Inquiry: Research for Change. Thousand Oaks: Sage Publications, Inc.

Rosenbloom, D., \& Kravchuk, R. (2005). PUBLIC ADMINISTRATION: Understanding Management, Politics, and Law In the Public Sector. New York: McGraw-Hill.

Scott, C., \& Jaffe, D. (1995). Managing Change At Work. Menlo Park: Crisp Publications, Inc.

Shepard, G. (2005). How To Manage Problem Employees: A Step-by-Step Guide for Turning Difficult Employees into High Performers. Hoboken: John Wiley \& Sons, Inc.

Thatchenkery, T., \& Chowdhry, D. (2007). Appreciative Inquiry and Knowledge Management. Northampton: Edward Elgar Publishing Limited.

Watkins, J., \& Mohr, B. (2001). Appreciative Inquiry: Change at the Speed of Imagination. New York: John Wiley \& Sons, Inc.

Whitney, D., Cooperrider, D., Trosten-Bloom, A., \& Kaplin, B. (2001). Encyclopedia of Positive Questions, Volume 1: Using Appreciative Inquiry to Bring Out the Best in Your Organization. Brunswick: Crown Custom Publishing. 
Whitney, D. \& Trosten-Bloom, A. (2002). The Power of Appreciative Inquiry: A Practical Guide to Positive Change. San Francisco: Berrett-Koehler Publisher, Inc.

Whitney, D., Trosten-Bloom, A., Cherney, J., \& Fry, R. (2004). Appreciative Team Building: Positive Questions to Bring Out the Best of Your Team. Lincoln: iUniverse, Inc.

Seligman, M., Positive Psychology. (2007). University of Pennsylvania Positive Psychology Center. Retrieved 27 February 2010 from the World Wide Web: www.ppc.sas.upenn.edu/

The following web sites provided AI general references:

http://appreciativeinquiry.case.edu/

http://www.taosinstitute.net 


\section{Appendix A}

\section{Agreement to Participate in Research}

Investigator: Mary Figone, San José State University Graduate Student

Title: Applying the Appreciative Inquiry Theory for a Work Group Development

The organization is a progressive one dedicated to the service of the public by productive employees working in a collegial atmosphere. Work group development is one technique designed to raise both employees' satisfaction in their work and customer satisfaction with the services received. This local government agency has determined that using Appreciative Inquiry (Al) will enable the members of this work group to improve their working relationships and job satisfaction. I will be administering the Appreciative Inquiry Project as an integral part of my work as your supervisor.

As part of my work towards my Master of Public Administration program at San José State University, I will also be documenting the benefits of the Al approach and the outcomes for our working group. In order to ensure that I have the most accurate information about the application of $\mathrm{Al}$ and its outcomes for our work group I would like to invite your participation in the feedback and evaluation of Al. While you are expected to participate in Al as part of your job, you are not required to participate in the research that I will do to evaluate Al's application.

1.) In order to complete my Master's program at San José State University, I will be doing a case study of the application of Al to see if the Appreciative Inquiry theory is helpful in the development of our work group.

2.) In order to ensure workplace productivity at our organization, this local government agency strives to create positive working relationships.

Appreciative Inquiry organizational development theory is a welldeveloped theory that has proven to improve work group outcomes, and will be applied as an integral part of the supervisor's activity within our work group.

3.) Your work-related participation in Al will involve completing two surveys; answering positive questions in an Al interview; and participating in a work group discussion regarding the Al interview. The research portion will involve including these materials and responses in the evaluation of Al. You may opt out of the research portion, meaning that your responses would not be used in this research project on Al.

Initial 


\section{Agreement to Participate in Research (continued)}

4.) The possible direct benefits to you from the use of Al at work would be to have a stronger work group and potentially an indirect benefit would be a more appreciative outlook in both your personal and professional life.

There would be no direct benefit to you from the research, but the indirect benefit would be a better understanding of outcomes from the application of Al theory so that more employees may benefit from the application of Al in the work group.

5.) Minimal risks are associated with this study, as there would be no impact on you from the study beyond the work-related activities that will be done.

6.) Since all Al work will be done during normal duty hours and within the context of your normal work, there will not be any additional compensation for participating in this study.

7.) There will be no identifying information of any kind in the case study. All surveys and notes will identify participants through codes only.

8.) This Al study will be applied from 10/13/09 thru 03/31/10.

9.) Questions about this research project may be addressed to Mary Figone. Complaints about this research may be presented to Dr. Frances Edwards, MPA Director, Political Science Department/San José State University, (408) 924-5559. Questions about a research subjects' rights, or research-related injury may be presented to Pamela Stacks, Ph.D., Associate Vice President, Graduate Studies and Research, at (408) 9242427.

10.) Your signature at the bottom of this form indicates your willingness to have your opinions and responses used as confidential data for the research.

11.) The investigator's signature on this form indicates agreement that you are a part of the study and that you have been fully informed about your participation rights.

12.) At the time that you sign this consent form, you will receive a copy of it for your records, signed and dated by the investigator.

Participant's Signature

Investigator's Signature

\section{Date}

Date 


\section{Appendix B}

\section{ECS Staff Surveys}

\section{ECS Staff Pre- and Post-Intervention Surveys}

This is a confidential survey and your participation would have a positive affect on your work team. Your work team is defined as you and the other Department support staff members.

1.) Please describe one situation where you felt energized working with your other work team members. What made this a positive experience for you and/or the team?

2.) What are your dreams for your work team?

3.) We are all unique individuals with many different skills and talents. What do you think are a few of your strengths and why did you choose them as your strongest ones?

4.) What are some of the strengths you see in your other team members?

5.) Have you received any positive recognition at work in the last 7 days?

6.) Have you provided any of your team members with positive recognition in the last 7 days?

7.) Each one of us has the ability to be a "leader" in our own way. We can perform our job duties with a positive attitude, take responsibility for our actions, and help to create a fun work environment, use supportive communication, and do our personal best in our jobs finding efficiencies wherever we can. Do you think you are currently being a "leader" in your job role why or why not?

8.) Do you think others perceive you as a leader? Why or why not?

9.) Do you enjoy being a part of a work team? Why or why not?

10.) If you were the "coach" of your work team, what constructive feedback would you give this team to make it the best team ever?

\section{Thank you far taking the time ta answer these surwey questians.}




\section{Appendix C}

\section{ECS Staff Pre-Intervention Survey Results}

Following are the survey questions and results:

1.) What are some of the strengths that you see in your team members?
a. Ability to work together during times of critical deadlines without hesitation.
b. Pulling together only when necessary.
c. Being supportive, flexible, organized, and knowledgeable.
d. Hard workers, they work together well, and they know their jobs.

2.) Have you received positive recognition at work in the last 7 days?
a. Yes - 2 (1 of 2 - Only by manager this morning)
b. No-2

3.) Have you provided any of your team members with positive recognition in the last 7 days?
a. Yes -2
b. No-1
c. I make sure to say thank you when it is warranted. 


\section{4.) If you were the "coach" of your work team, what constructive feedback would you give this team to make it the best team ever?}

a. Set attainable goals but aim high; learn all you can; if you want to make a difference you need to first learn the process; and do not try and change something you do know anything about.

b. Work together as a team.

c. Work together as a unit; be dependable especially in times of crisis; and they adapt to situations.

d. Communicate more effectively: be specific, ask questions, confirm your understanding; smile at each other; and be nice.

\section{5.) Do you enjoy being a part of a work team? Why or why not?}
a. Yes, I like camaraderie.
b. Sometimes, there are times I don't feel part of the team.
c. Sometimes, when it comes to a group project, but other times I prefer to work on my own on specific parts of the project that requires analysis.
d. I enjoy being part of a "functional” work team.

\section{6.) Do you think others perceive you as a leader? Why or why not?}

a. Yes, because I can get things done without any fuss.

b. Yes, because I can achieve more than one task at a time and am willing to take the initiative and learn something new.

c. No, because they think I am the new kid on the block.

d. I am not sure how to respond to this. I really do not know because I have not received feedback from co-workers in this area except for one 
co-worker that has commented favorably on my leadership qualities.

7.) Each one of us has the ability to be a "leader" in our own way. We can perform our job duties with a positive attitude, help to create a fun work environment, use supportive communication, and do our personal best in our jobs finding efficiencies wherever we can. Do you think you are being a "leader" in your job role? Why or why not?

a. Yes, because I take the initiative to learn and work outside of the box. I show others that it can be done if they want to do it. I lead by example.

b. Yes, I like to help people.

c. Yes, I think I am. I always share my ideas and help others when they are stuck looking ways to improve or even complete a task. I share my knowledge of processes that have been successful with others who will benefit, I offer my experiences and skills in areas that would encourage and enhance others' skills and techniques. I am always willing to listen to problems or troubles that are affecting performances or behavior in a negative way, and am always willing to work together to find solutions together. I make myself approachable at all times.

d. Yes, because I am an example of flexibility with a positive attitude. 


\section{Appendix D}

\section{ECS Staff Post-Intervention Survey Results}

\section{What are some of the strengths you see in your other team members?}

- They are flexible and hard working.

- I see minimal strengths in the majority of my team members. Those who do possess these qualities are goal oriented, ready to step up to the plate, and to get the job done.

- They have a willingness to get the job done.

- They are all able to do their work.

- They are willing to provide backup and other assistance when asked.

2. Have you received any positive recognition at work in the last seven days?

- Yes - 3

- $\quad$ No - 2

3. Have you provided any of your team members with positive recognition in the last 7 days?

- $\quad$ Yes - 3

- $\quad$ No - 2

4. If you were the "coach" of your work team, what constructive feedback would you give this team to make it the best team ever?

- They learn to communicate more frequently. 
- I do not think there is any "constructive feedback" that could be given to make this team as a whole the best team ever.

- They should help one another because teamwork is important.

- They should just come to work and do the best of their ability in their jobs.

- Communicate more effectively so awareness of job situations is available to all.

\section{Do you enjoy being a part of a work team? Why or why not?}

- Yes, it makes all of our jobs easier in some ways.

- I do enjoy being a part of a work team on most days.

- Yes, I like working in this department.

- Yes, when I am working on a real team.

- Sometimes I enjoy being a part of a work team. Joint projects are beneficial to working together, but sometimes when it comes to personal strengths, it is better to work alone in achieving my goal.

\section{Do you think others perceive you as a leader? Why or why not?}

- $\quad$ Some people do and some do not because we have strong personalities in our group.

- Yes, because I try to lead by example.

- Yes, I have worked here for a long time and I know how to get along with people.

- I do not know.

- I do not know.

7. Each one of us has the ability to be a "leader" in our own way. We can perform our job duties with a positive attitude, help to create a fun work environment, use supportive communication, and do our personal best in our jobs finding efficiencies wherever we can. Do 


\section{you think you are being a "leader" in your job role? Why or why not?}

- I believe that I am a leader because I set a good example of being positive.

- Yes, I am not afraid to take on new and/or additional work which will challenge me. I also try and make sure that I convey a "sunny disposition" throughout the day with whomever I come into contact with.

- Yes, I have the ability to assist the staff without making them feel bad.

- Yes, I do my work with a positive attitude and help others.

- Yes, I am because I communicate effectively, ask questions, and deal with issues on my level instead of going to my manager all the time. I make myself approachable for whatever and whenever the need arises. I deal with situations right away.

\section{New Question: What did you learn from participating in the Appreciative Inquiry 4-D cycle process with your work group?}

- It was beneficial because it brought everyone together to achieve a goal of improving our team.

- I thought it was good to go through the steps of the AI, however, saying, doing, participating and following through are all different functions. Without complete positive commitment from all, this is just another training exercise that will not work in the end.

- We have one thing in common. We need our jobs.

- We are all different - our opinions, outlooks, goals, styles, values, and 
principles. We have the same basic needs - respect, flexibility, and the desire to be ourselves.

\section{New Question: Do you think any other groups would benefit from the Appreciative Inquiry experience and why or why not?}

- Yes, because teams will learn in a practical way how to improve their cohesiveness.

- Yes, it might work for other groups.

- Yes, I agree other groups would benefit from an Appreciative Inquiry experience.

- No, the amount of time does not match the amount of change.

- Yes, because they can learn from each other; to discover what is the ultimate goal; respect one another's values and principles; and learn to work together with better communication.

\section{Appendix E}




\section{Other Key Staff Survey}

Other Key Staff Pre- and Post-Intervention surveys

In an effort to improve both the internal and external services we are providing to our customers, I am doing an informal survey regarding your perceptions of the strengths of the support staff team. Your participation in this survey would be very helpful. The support staff team is defined as five member support staff group. (This information will be kept confidential.)

1.) Are you currently satisfied with the quality of service that you are receiving from the support staff? Please explain why or why not.

2.) Is your support staff available when you need them?

3.) What strengths do you see in your support staff and the whole support staff team?

4.) In the area of customer service, what do you see as strengths in the whole support staff team?

5.) What are your suggestions to strengthen the overall support staff team's effectiveness?

6.) Do you have any other feedback on the support staff team that you would like to share?

\section{Thank you for taking the time to answer these swrey questians.}

\section{Appendix F}




\section{Other Key Staff Pre-Intervention Survey and Results}

\section{1.) Are you satisfied with the quality of service that you are receiving from your support person? (Please explain why or why not.)}

\section{Doing well:}

- Yes, generally satisfied with the support.

- There is the perception that some of the support staff members provide quality support while others provide fair to poor support.

- Some support staff members are better at anticipating the needs of the department and taking steps to address those needs without specific definition. This is called being proactive and having initiative.

- Yes, I am satisfied. I work with several support staff and find them to be responsive and helpful to me at all times. I have also observed or overheard their work with the public, on the phones, and in person and am impressed at how professional and courteous they are to the public.

\section{Areas for Improvement:}

- Support is fragmented given that each person works for a variety of people. There may be days when the need requested from one work group member conflicts with the needs of another work group member and each member is on a short turnaround. This situation is being addressed only in response to the need at the time. Maybe there is a way to avoid the time conflict in the first place. 
- It is also clear that the interpersonal relationships between support staff members affect the overall quality of work of the team. Finally, I get the sense that the department has an emphasis on making the support staff "happy" more so than the other employee groups. I do not have a problem with this as long as it improves the work quality of the support staff team.

- Generally, service is satisfactory if the requests fall within what the support person considers standard and/or if it does not have to be done right away.

2.) Is your support person available when you need her? (If not, explain why.) Doing well:

- Yes - 8 survey respondents

- Usually/Generally - 4 survey respondents

- She is generally available, but I cannot say that I can always count on her to be available when I need her.

\section{Areas for Improvement:}


- If the person is consistently out in the beginning of the week or the last day of the week, I start to wonder about reliability. It is not a major issue since I am capable of doing the work myself.

- Oftentimes, when I go to ask a support staff person a question they are not at their desk and they have not signed out on the white board.

- There are times when support staff is not around.

- Yes, generally they are available at all times. The support staff person that I use the most makes a definite effort to plan ahead with her workload, especially if she knows she will be out of the office for a vacation or other reasons.

- I tend to complete tasks which should be support staff tasks. It reduces my effectiveness in my position. However, when my support staff person is available and I request a task to be completed, it does get done quickly and effectively.

\section{3.) What strengths do you see in the support staff team?}

\section{Doing well:}

- They are all very helpful in assisting their individual person or persons that they support. Also, they are very informative and knowledgeable in the things that they do. 
- Generally, support staff understands that they are part of a team and back-up each other when needed.

- I think that for the most part the team is responsive and helpful.

- I think they are all capable individuals with separate skills and strengths. Most of them have a long tenure with the Department.

- Our Department is very deadline driven therefore requiring very organized people to make sure that deadlines are met. There is a lot that goes into making the deadline outside of the work we do that requires strong organizational and time management skills. For the most part our support staff does a good job dealing with these tasks.

\section{Areas for Improvement:}

- The support staff team is able to get their basic jobs done. Sometimes they are friendlier than at other times.

- They all can generally pull together in a crisis situation.

- The one area that I think deserves the most focus is the concept of "teamwork" they may support each other when needed or required but they do not seem to do it voluntarily. 
- There seems to be a desire to work together amongst the members, which is a good sign. Although it will be helpful to continue the cross training so they are able to fill each other's shoes, when needed.

- However, there could be improvements in this area. Especially when there is only one or two support staff at work, then more effort may be needed to be sure that a call or walk-in customer gets the help they need or that requests from other departments get directed to the right person.

\section{4.) Please provide any additional comments/suggestions for improvements, if any.}

\section{Areas for Improvement:}

- The support staff needs to work in better coordination with each other. They need to improve their attitude in helping "other staff” which they are not supporting. They go to them only under extenuating circumstances.

- Feels like there is a lack of willingness by the support staff members to help other employees supported by other support staff members.

- When my support staff person is gone, no one automatically steps in to see how they can be sure that all aspects of the office are being covered. You feel on your own when she is out of the office. There are "invisible lines" that people do not want to cross. 
- More cross training. It might be helpful for the $5^{\text {th }}$ floor support staff to meet periodically with the Off-site Center support staff (maybe include the counter technicians) to improve communications and the process of referring customers between the regular floor and the Off-site Center.

- Support staff assignments and duties should reflect the goal of improving the function and operation of support staff and the Department, rather than what might be considered "fair” or "unfair” to an individual support staff member.

- Training on time management skills and how to cope when workload increases.

- Support staff does not have a real commitment to any larger department mission or going above and beyond. Never have I been asked, “May I help you with that?” or "Is there something I could do to reduce the time crunch you are under?”

- More teamwork, initiative, pride in the work, and personal responsibility and less bickering and the typical "that's not my job” attitude. 


\section{Appendix G}

\section{Other Key Staff Post-Intervention Survey and Results}

\section{Are you satisfied with the quality of service that you are receiving from your support person? Please explain why or why not?}

- Yes

- Yes

- For the most part I am, but I wish my support staff could be more like Judy Doe when it comes to support for hearings. Judy Doe reminds you of what she needs from you and when and in a friendly way stays on you until she gets it. She follows up and makes sure it gets done.

- Not really, the current support structure is neither efficient nor effective.

- Yes, one of them is very responsive to inquiries and follows through on issues even when she does not know the answer immediately. Another one of them is also a great assistance when working on projects for the Planning and Transportation Commission or City Council.

- The key word is "support" - not that I am so busy I cannot be interrupted by anyone today. 
- No, they do not take any initiative about their work. I see them standing around talking a lot.

- Somewhat. Certain members provide good service and a few have negative attitudes.

- Yes, her return calls for the department are a primary service; drafting letters has become noticeably better in quality and error correction.

\section{Is your support person available when you need her? (If not, explain why.)}

- Yes

- Yes

- Typically yes.

- No, other priorities supersede my need for a support person.

- Most of the time. She has thoughtfully put a sign on her chair when she is working at the front counter so that she is still available for questions.

- Not really - off doing other things.

- Oftentimes, I have trouble finding any of the support people. They do not consistently use the white board.

- Yes

- I often have to hunt someone down.

- Yes 


\section{What strengths do you see in your support staff member?}

- My support staff member is efficient and cooperative.

- Cooperative team member she knows her job inside and out and has

a great understanding of the internal processes. She can be friendly

most of the time. There are times that clearly the internal politics of this office

frustrate my support person to the point where it is noticed.

- An interest in doing and learning more and a willingness to help figure out the solution to a problem.

- $\quad$ She is punctual.

- The biggest strength she has is being strong-willed.

- She is increasingly versed in variable tree-related questions and on other question and answer issues posed to the department arborist.

\section{What strengths do you see in the support staff team?}

- $\quad$ They are friendly and hard working.

- There is more of a willingness to help other staff. 
- There seems to be a lot of cross knowledge between them, but they also tend to run very hot and cold with each other.

- There are no strengths that I see in the support staff team.

- A general willingness to help each other and answer questions, even when from someone that is not in their primary section.

- They do not appear to be a team. There is lots of bickering going on.

- The support staff team knows how to fight effectively. They need to focus on their jobs and think about the people that they are supporting.

- There seems to be more of camaraderie in the team.

\section{Have you seen any positive changes in the support staff team, in the last six months, since you took this original survey?}

- Better clarification on who is responsible for what task and being able to go to any staff member for help.

- They generally seem to be more supportive, friendly, and willing to do what is needed to help out.

- None whatsoever.

- Nothing specific.

- No 
- Their attitude does seem a little bit better, but they still do not go above and beyond in their working as a team.

- No

- Yes

\section{Please provide any additional constructive comments/suggestions with examples for improvement areas for the Support Staff group, if any.}

- Need more automatic follow up on mailing affidavits

- I have no idea how to resolve the sometimes visible personality conflict issues that arise from time to time, but I believe that service would be improved if the staff could follow the example set by Jane Doe when it comes to items going to hearing. This would be beneficial not just for hearings, but for all tasks if there was more check-in with the staff on newspaper adds, notice cards, etc. This kind of communication would help to ensure that items make it on the agenda for hearings and that proper noticing gets done and the proper documentation gets into the files. Currently, it feels like hit and miss when it comes to certificates of mailing making their way to the appropriate staff for the public file. Also, after items have gone to hearing making sure that signed documents come back to us from Clerk's Office and getting items into the files e.g., Resolutions, ROLUAs, and PC ordinances.

- Keep trying and working hard. 
- The Support Staff group needs to focus on their jobs and not on other people. They are so worried about everything being fair. If they would just do their jobs to the best of their abilities and stop worrying about what everyone else is doing, then they would be a much stronger group.

- I feel that I do not know the complete scope of services that our support staff can, or are responsible for providing. A list of "what your support staff person can do for you" would be helpful. I do not always know what is appropriate to ask of them and feel like I could be utilizing them more.

- All support staff should be able to disburse information (handouts, Frequently Asked Questions, tree removal permits, etc...) that the department is responsible for. 


\section{Appendix $\mathbf{H}$}

Introduction to Appreciative Inquiry

\section{(Power Point)}

(These are six slides that provided an AI introduction to the group. I cannot get the Power Point print page layout to copy so I will have to insert this page and copy the following page onto it for the final paper.) 


\section{Appendix I}

\section{Discovery Phase: AI Themes Summary Chart}

\begin{tabular}{|c|c|c|c|c|c|c|}
\hline \# & $\begin{array}{l}\text { Opening- } \\
\text { Core factors } \\
\text { that give life } \\
\text { to this } \\
\text { organization }\end{array}$ & $\begin{array}{l}\text { Effective/ } \\
\text { Compelling } \\
\text { Communicatio } \\
\text { n-Key Factors }\end{array}$ & $\begin{array}{l}\text { Creating/Sustaining } \\
\text { Positive Energy- } \\
\text { Key Factors }\end{array}$ & $\begin{array}{l}\text { Respect for } \\
\text { People- } \\
\text { Key Factors }\end{array}$ & $\begin{array}{l}\text { Winning } \\
\text { Teamwork } \\
\text {-Key } \\
\text { Factors }\end{array}$ & Conclusion- 3 Wishes \\
\hline 1 & $\begin{array}{l}\text { Diversity, culture, } \\
\text { each individual's } \\
\text { essence - makes it } \\
\text { vibrant here! }\end{array}$ & $\begin{array}{l}\text { Listen, understand, } \\
\text { and put yourself In } \\
\text { the other person's } \\
\text { shoes. Tell what I } \\
\text { am trying to say and } \\
\text { ask clarifying } \\
\text { questions. }\end{array}$ & $\begin{array}{l}\text { Everybody felt: they } \\
\text { belonged; they were } \\
\text { important; they were involved } \\
\text { in everything; and they were } \\
\text { brought together for } \\
\text { announcements. "Knowledge } \\
\text { Is The Key to Success." }\end{array}$ & $\begin{array}{l}\text { Getting to know } \\
\text { who you are. This } \\
\text { will lead you to } \\
\text { know more about } \\
\text { respecting others. }\end{array}$ & $\begin{array}{l}\text { Knowledge of } \\
\text { project; } \\
\text { people's } \\
\text { willingness to } \\
\text { help; common } \\
\text { goal } \\
\text { (stakeholders } \\
\text { involved); } \\
\text { availability of } \\
\text { tools; and } \\
\text { camaraderie. } \\
\end{array}$ & $\begin{array}{l}\text { Wished for more money to } \\
\text { buy state of the art } \\
\text { equipment; separation of } \\
\text { work and play; and one for } \\
\text { all or all for none. }\end{array}$ \\
\hline 2 & $\begin{array}{l}\text { In the past, this } \\
\text { organization cared } \\
\text { about the } \\
\text { employees; valued } \\
\text { me; liked the way } \\
\text { the executive } \\
\text { people knew me } \\
\text { by name. It felt } \\
\text { like a family. }\end{array}$ & $\begin{array}{l}\text { Tactfulness; } \\
\text { sincerity; listening } \\
\text { more than telling; } \\
\text { and being honest. }\end{array}$ & $\begin{array}{l}\text { Open and positive attitudes; } \\
\text { worked hard and played hard } \\
\text { (e.g., golf/lunch played games } \\
\text { and team activities that } \\
\text { everyone enjoyed). }\end{array}$ & $\begin{array}{l}\text { Frequent } \\
\text { communication } \\
\text { and taking } \\
\text { personal time with } \\
\text { me. }\end{array}$ & $\begin{array}{l}\text { Respect; open } \\
\text { communication } \\
\text {; having fun } \\
\text { together; very } \\
\text { positive; and } \\
\text { no backbiting. }\end{array}$ & $\begin{array}{l}\text { Wished everyone respected } \\
\text { each other; that everybody } \\
\text { would be included in the } \\
\text { group; and everyone be } \\
\text { happy in their job. }\end{array}$ \\
\hline 3 & $\begin{array}{l}\text { A year ago, the } \\
\text { organization's } \\
\text { positive core was } \\
\text { that it cared about } \\
\text { its' employees; } \\
\text { defended its' } \\
\text { employees against } \\
\text { community } \\
\text { members; and it } \\
\text { was willing to } \\
\text { work with the } \\
\text { employees. }\end{array}$ & $\begin{array}{l}\text { Honesty; } \\
\text { truthfulness; being } \\
\text { able to listen; and } \\
\text { conveying } \\
\text { suggestions or } \\
\text { advice, if } \\
\text { warranted. }\end{array}$ & $\begin{array}{l}\text { A story was shared about the } \\
\text { reactions of employees in a } \\
\text { former company during an } \\
\text { earthquake. The situation was } \\
\text { not funny, but their reactions } \\
\text { to it were. }\end{array}$ & $\begin{array}{l}\text { She goes above } \\
\text { and beyond when } \\
\text { doing her work } \\
\text { and because of this } \\
\text { she receives thank } \\
\text { yous from many } \\
\text { sources. She has } \\
\text { extreme pride in } \\
\text { her work and } \\
\text { continually strives } \\
\text { to improve. }\end{array}$ & $\begin{array}{l}\text { Pulling } \\
\text { together to } \\
\text { work as a team; } \\
\text { getting the job } \\
\text { done on time } \\
\text { and correct; no } \\
\text { worries on } \\
\text { getting the job } \\
\text { done on time } \\
\text { just knowing it } \\
\text { would get } \\
\text { done; and } \\
\text { having trust in } \\
\text { your co- } \\
\text { workers. }\end{array}$ & $\begin{array}{l}\text { Wished that they all would } \\
\text { be treated as individuals and } \\
\text { the jobs they are doing even } \\
\text { though they are similar; } \\
\text { when a decision is made } \\
\text { following } \\
\text { through on it; and continuity } \\
\text { regarding the workload. }\end{array}$ \\
\hline 4 & $\begin{array}{l}\text { The people in this } \\
\text { organization give } \\
\text { it life. The } \\
\text { passion for the } \\
\text { work and service } \\
\text { to the community } \\
\text { and residents. }\end{array}$ & $\begin{array}{l}\text { Being clear when } \\
\text { expressing oneself; } \\
\text { having a } \\
\text { professional } \\
\text { approach; being } \\
\text { open to feedback; } \\
\text { and realize that one- } \\
\text { sided } \\
\text { communication } \\
\text { does not work. }\end{array}$ & $\begin{array}{l}\text { Lunchtime gatherings with } \\
\text { outside food and movies. This } \\
\text { was an outlet to share } \\
\text { concerns. Warm feelings } \\
\text { developed here and carried } \\
\text { into the work. This was a fun } \\
\text { monthly event that we all } \\
\text { looked forward to and it } \\
\text { improved our attitudes. }\end{array}$ & $\begin{array}{l}\text { Camaraderie and } \\
\text { fun! }\end{array}$ & $\begin{array}{l}\text { Excellent } \\
\text { communication } \\
\text { and a } \\
\text { professional } \\
\text { manager. } \\
\text { Manager } \\
\text { motivated his } \\
\text { employees to } \\
\text { strive to be } \\
\text { their best. }\end{array}$ & $\begin{array}{l}\text { Wishes that the manager she } \\
\text { supports could have better } \\
\text { time management skills; } \\
\text { wishes that processes could } \\
\text { be better and that support } \\
\text { staff could help to build or } \\
\text { redo the processes; and that } \\
\text { the morale could be lifted for } \\
\text { the entire department. }\end{array}$ \\
\hline 5 & $\begin{array}{l}\text { The internal staff } \\
\text { and my } \\
\text { interactions with } \\
\text { them and also my } \\
\text { interactions with } \\
\text { the public. There } \\
\text { are positive } \\
\text { aspects in both. }\end{array}$ & $\begin{array}{l}\text { Let the party know } \\
\text { where you are; keep } \\
\text { your Outlook } \\
\text { calendar up to date; } \\
\text { use the time-out } \\
\text { calendar; write } \\
\text { notes and leave it } \\
\text { on your files } \\
\text { regarding project } \\
\text { status; update } \\
\text { people around you } \\
\text { on what is going on; } \\
\text { and use good } \\
\text { follow-up. }\end{array}$ & $\begin{array}{l}\text { Having another employee who } \\
\text { is caring and considerate of } \\
\text { her; the annual Christmas } \\
\text { lunch party; and the } \\
\text { Halloween potluck and } \\
\text { costumes. }\end{array}$ & $\begin{array}{l}\text { Providing full } \\
\text { support to her } \\
\text { staff; respect is } \\
\text { something you } \\
\text { earn; she respects } \\
\text { the group she } \\
\text { supports; it is a } \\
\text { two-way street; } \\
\text { and she follows-up } \\
\text { with them like she } \\
\text { would do with the } \\
\text { public. }\end{array}$ & $\begin{array}{l}\text { Think about } \\
\text { the team and } \\
\text { how to achieve } \\
\text { the team's goal } \\
\text { and not the } \\
\text { individual. It } \\
\text { does not matter } \\
\text { how small or } \\
\text { big the step is } \\
\text { since they all } \\
\text { add up to a big } \\
\text { achievement. }\end{array}$ & $\begin{array}{l}\text { Wishes that the officials } \\
\text { would think also about the } \\
\text { employees. Wishes that in } 6 \\
\text { months there will be a good } \\
\text { contract for the employees. } \\
\text { Wishes that there would be } \\
\text { more open supportiveness to } \\
\text { ideas that could improve the } \\
\text { team. }\end{array}$ \\
\hline
\end{tabular}




\section{Appendix $\mathbf{J}$}

\section{Personal Discovery}



\section{What is a Typical Day for Mary?}

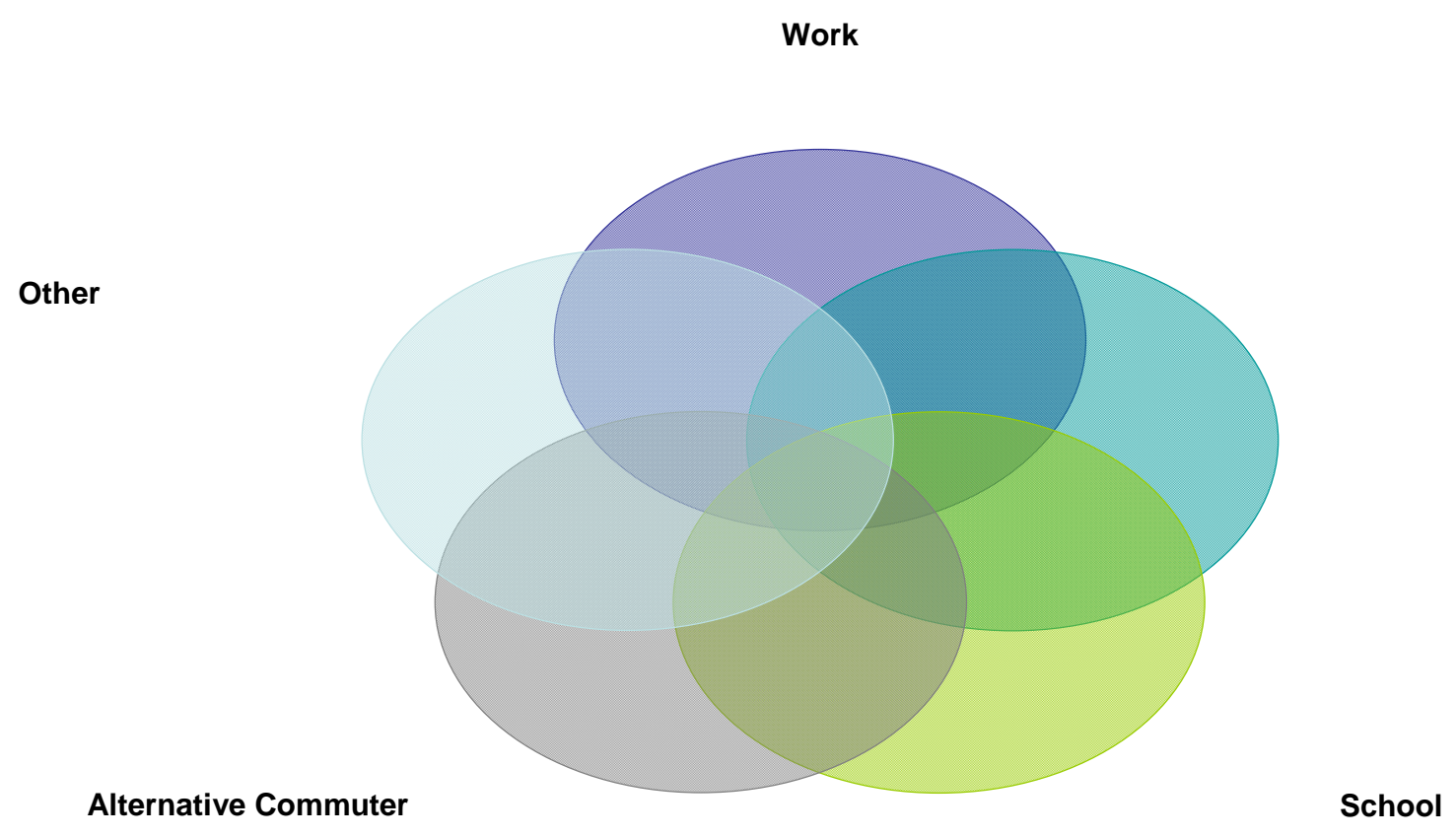

\section{What is a Typical Day for You?}

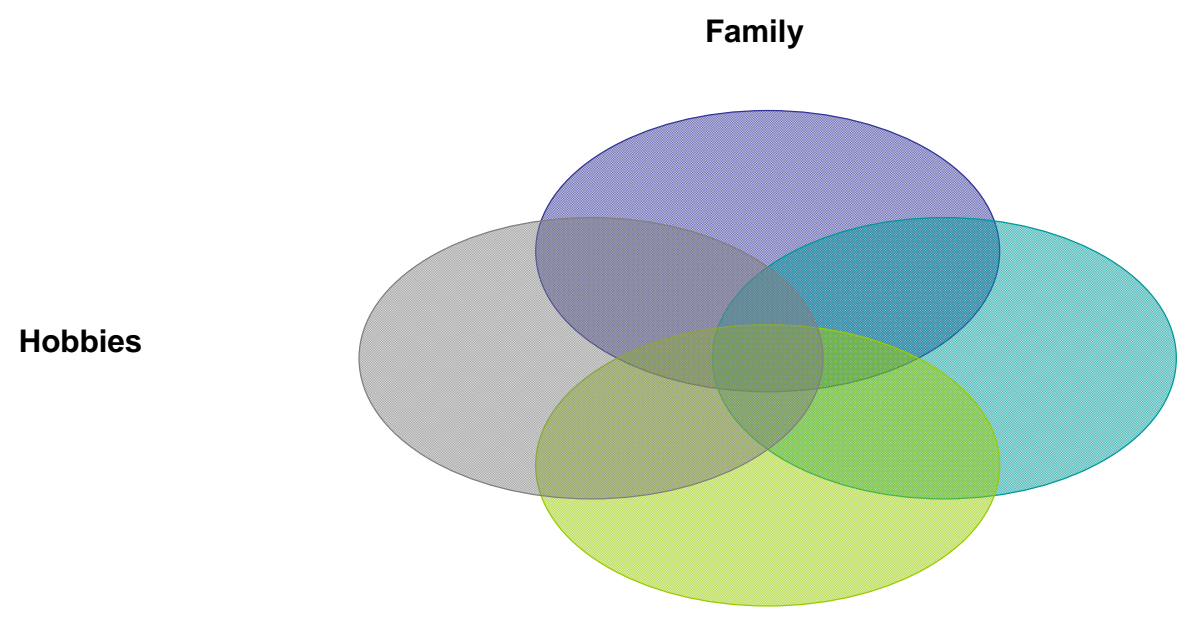

Work

Religion 


\section{What Do You See As Your Strengths?}

- Caring and supportive

- Hard worker

- Have initiative

- Organized

- Persistent

- Team player

\section{What Areas of Yourself Would You Like To Be Stronger In?}

- Delegating work

- Making more time for fun and my hobbies

- Learning more about technology 


\section{Appendix K}

\section{ECS Staff Procedures Updated: $01 / 10$}

- $\quad$ Arrive to Work on Time: If you are going to be late or absent, please notify your supervisor (323-1549) by 7:30 a.m. You also must call x2332 and leave a message.

- Extended Periods of Time-off: Please change your telephone voicemail message if you are planning on an extended period of time off.

- Leave Work on Time: If you leave work early for any reason, you must notify your supervisor. Any Overtime needs to be pre-approved by your supervisor.

- White Board: Please keep the white board up to date if you are leaving the floor with your location and the time when you will return to the office.

\section{BREAKS}

- You have two 15 minute breaks that may be taken one in the morning and one in the afternoon. If you do not take your break, then you lose that time.

- You have a choice between either a 30 or 60 minute lunch break to be taken between 12:00 and 1:00 p.m. (Please verify with me what your specific lunch time is.)

\section{MISCELLANEOUS OFFICE PROTOCOL}

- Any overtime work must be pre-approved by your supervisor.

- Please turn off computer, radio, and any lights at your desk when you leave the office.

\section{TIMECARDS}

- Please follow the Department's deadline for time card preparation. Timecards are normally due on Wednesdays of the non-9/80 Friday week. If you will be out of the office when timecards are due, please fill out time cards in advance of your leave.

\section{SCHEDULING TIME OFF}

- All time-off requests should be submitted in advance. There must be extenuating circumstances to submit them on the same day.

- Your time-off is not approved until written confirmation is provided by your supervisor.

- If you have questions or concerns, please bring them to your supervisor's attention. 


\section{INAPPROPRIATE CONVERSATION}

- All conversations shall be professional and appropriate to the work place.

- Please focus on your work during your work shift.

\section{POLICIES AND PROCEDURES}

- A Policies and Procedures manual and the City's Merit Rules are available on the intranet or in ESS.

- Each employee should read, become familiar with, and follow established city protocols.

IN PARTICULAR...

1-40/ASD USE OF COMPUTER

2-13/HRD SEXUAL HARASSMENT

2-18/HRD ALCOHOL AND DRUG ABUSE

2-21/HRD GIFTS AND GRATUITIES

3-01/HRD SAFETY POLICY 


\section{Appendix L \\ ECS Team Contract (Keys to a Highly Successful Team)}

1. Let us think twice about what we are about to say. Is the topic better to discuss privately, "off line" with your supervisor or with the individual? Is it appropriate for the whole group to discuss, and will it spark negativity in the group?

2. Let us look for positive solutions together.

3. Let us focus on speaking up honestly in a positive manner.

4. Let us anticipate issues and resolve them in a timely manner.

5. Let us proactively communicate and collectively solve problems.

6. Let us show a willing attitude. Be helpful and "jump in."

7. Let us be committed to the assignment and to the team until the job is completed. If each person gives 100 percent, there will be no resentment by others on the team.

My signature below demonstrates my commitment to the team and to the seven items above.

Employee 1

Employee 2

Employee 3

Employee 4

Employee 5

Researcher/Supervisor

Date: 


\section{Appendix M}

\section{The New Workplace: Where Are We Going? Checklist}

Below are the elements from Managing Change At Work that can be expected in most organizations in 2000 and beyond (Scott \& Jaffe, 1995, p. 7). At the end of each element, there is a ${ }^{1}$ for the elements that the team members would like and $\mathrm{a}^{2}$ for those elements that the supervisor/researcher would like to see occur.

More employee involvement in all levels of decision making ${ }^{1,2}$

$\square$ Increased emphasis on "meaningful work"2

More responsibility and accountability for individual employees ${ }^{2}$

$\square$ Fewer managers and more participation in the form of self-managing teams ${ }^{1,2}$

People responsible for their own skill development ${ }^{1,2}$

A focus on human capital as demonstrated by an investment in training, retraining and new skill development ${ }^{1,2}$

An atmosphere that encourages more mutual respect and trust ${ }^{1,2}$

A continuous need for learning ${ }^{1,2}$

An increase in the protection of employee rights ${ }^{1}$

$\square$ Programs that support balancing work and family life $\mathrm{e}^{1,2}$

Increased encouragement of learning and creativity away from the workplace via tuition and fee reimbursement plans ${ }^{1,2}$

$\square$ Better recognition and reward for superior performance $e^{1,2}$ 